\title{
WestVirginiaUniversity
}

THE RESEARCH REPOSITORY @ WVU

Graduate Theses, Dissertations, and Problem Reports

2009

\section{(re)construct: exploring objecthood in a digital age}

Patrick L. Jones

West Virginia University

Follow this and additional works at: https://researchrepository.wvu.edu/etd

\section{Recommended Citation}

Jones, Patrick L., "(re)construct: exploring objecthood in a digital age" (2009). Graduate Theses,

Dissertations, and Problem Reports. 3292.

https://researchrepository.wvu.edu/etd/3292

This Thesis is protected by copyright and/or related rights. It has been brought to you by the The Research Repository @ WVU with permission from the rights-holder(s). You are free to use this Thesis in any way that is permitted by the copyright and related rights legislation that applies to your use. For other uses you must obtain permission from the rights-holder(s) directly, unless additional rights are indicated by a Creative Commons license in the record and/ or on the work itself. This Thesis has been accepted for inclusion in WVU Graduate Theses, Dissertations, and Problem Reports collection by an authorized administrator of The Research Repository @ WVU. For more information, please contact researchrepository@mail.wvu.edu. 


\title{
(re)construct: exploring objecthood in a digital age
}

\author{
Patrick L. Jones \\ Thesis submitted to the \\ College of Creative Arts \\ at West Virginia University \\ in partial fulfillment of the requirements \\ for the degree of \\ Master of Fine Arts \\ with \\ an emphasis in painting \\ Naijun Zhang, M.F.A., Chair \\ Victoria Fergus, Ph.D. \\ Kristina Olson, M.A. \\ Erika Osborne, M.F.A. \\ Michael Sherwin, M.F.A. \\ Division of Art and Design \\ Morgantown, West Virginia \\ 2009
}

Keywords: Painting, Photography, Contemporary Art, Jean Baudrillard Copyright 2009 Patrick L. Jones 


\section{$\underline{\text { Abstract }}$ \\ (re)construct: exploring objecthood in a digital age}

Patrick L. Jones

The following paper describes the conceptual framework and several works in the exhibition: "(re)construct: exploring objecthood in a digital age," which was on view at the Laura Mesaros Gallery at the College of Creative Arts, West Virginia University. The exhibition ran from November $30^{\text {th }}$ through December $11^{\text {th }}, 2009$. The exhibition consisted of both oil paintings on clear acrylic and ink jet photographs. The question which this paper and the exhibition attempts to address is: what are the ontology and the limits of hyperreality in contemporary society? The following paper and the exhibition is epistemologically based and asks the following questions: Are we in a continuous state of the hyperreal, as theorist Jean Baudrillard (1929-2009) suggested, or are we in a state of flux between the real and the hyperreal? And further, what place does the handmade play in contemporary society and art making? The work and the paper assert that the handmade, the sense of objecthood and physical manipulation in the works, dislocates the digital referent, which is suggested through both process and image. 


\section{Contents}

Acknowledgments............................................................................iv

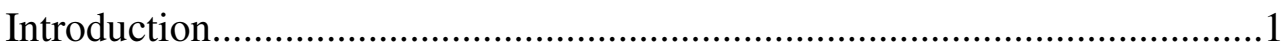

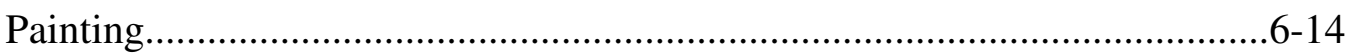

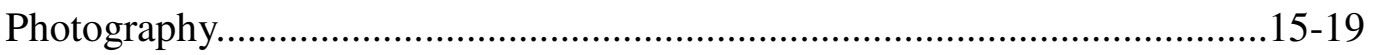

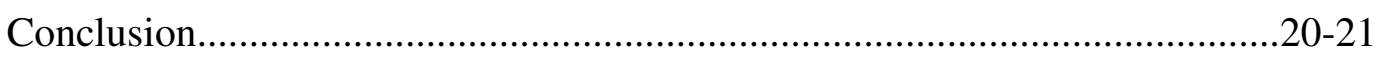

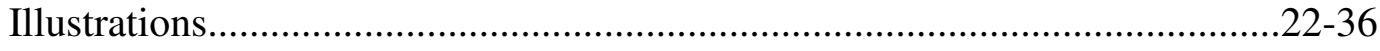

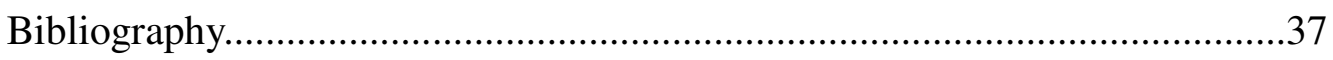

Appendix A: Works from the Exhibition.....................................................38-52

Appendix B: Curriculum Vitae......................................53-57 


\section{$\underline{\text { Acknowledgments }}$}

I would like to thank the members of my committee for their guidance and patience throughout the process of making the works for this exhibition and paper. I would also like to thank my family, in particular, my wife, Misty Chinault Jones, and daughter, Dorian Elizabeth Jones, who have often sacrificed my being-there for the time necessary to complete the works for the exhibition and this document. Lastly, I would like to dedicate this document and the works in the exhibition to my mother, Patricia Blanche Jones (1943-2006), who preceded this exhibition in death, but whose spirit and determination was felt through the entire process. 


\section{$\underline{\text { Introduction }}$}

To say that technology is ubiquitous today may very well be an understatement. Technology is integrated into our very existence. Twenty years ago, pay phones were on almost every corner. Now finding a pay phone outside of a truck stop or airport is almost impossible, the only places one can to find one. Most everyone has a cellular phone. I remember when cell phones were luxury items, but today all strata of society carry them. Cellular telephones, as anyone who has gone into a retailer will tell you, are not simply telephones. They are computers with a myriad of functions. These objects can easily provide images, video and the Internet. How often do we see people walking and texting, surfing the Internet, receiving pictures, etc. on these "phones." Perhaps, even more than the invention of the personal computer, this new hand-held computer, which we still archaically call a "phone" has removed us from reality and placed within the 'palm of our hands' the hyperreal.

The idea of the hyperreal is not a new one. The French philosopher Jean Baudrillard (19292009) described the hyperrreal in his book Symbolic Exchange and Death in 1976. The hyperreal is defined as that which is 'more real than real.' Baudrillard argued in 1976 that we more than prefer this reality, but that "today reality itself is hyperrealist." In 1976 the "information age" was in its infancy. Baudrillard none-the-less believed society to be in a state of the hyperreal. Baudrillard died this year seeing the near fulfillment of his "prophesy." We have gone fully from an analogue society to a digital one. Our lives are made up of binary codes, whether we acknowledge it or not. When television switched in February 2009 to digital signals, it was truly an end of an era.

When I began my MFA in 2005, the Gulf War II or "Operation Iraqi Freedom" was in full swing and the media machine bombarded its viewers with images of destruction and "victory." I was obsessed with these images, which mediated the war. I remember watching the first Gulf War on television and how banal it was to view due to its continuous coverage. Gulf War II was different with its media

\footnotetext{
${ }^{1}$ Jean Baudrillard, Symbolic Exchange and Death, Fom Modernism to Postmodernism: An Anthology, edited by Lawrence E. Cahoone (Cambridge, MA: Blackwell Publishers Inc., 1996), 456.
} 
coverage. Instead of a mindless steam of information, the media coverage was made to be "explosive." No matter upon which side of the political aisle one sat, which shifted with the networks, one thing was certain: nearly every night something exploded. I began to see this as a possible source material for my paintings. The imagery was intended to frighten us and yet we watched. It was tantamount an experience of the sublime- a $19^{\text {th }}$ century modality in a $21^{\text {st }}$ century war.

We became a war mongering culture with these insidiously beautiful images of destruction, death and despair. Perhaps, it was the images of humiliation and torture seen in the snapshots taken by interrogators and military personnel at the prison in Abu Ghirab that changed the American psyche, revealing the gratuitous nature of the imagery that was being consumed. In the Conspiracy of Art, Baudrillard commented by stating, "The worst is that it becomes a parody of violence, a parody of the war itself, pornography becoming the ultimate form of the abjection of war which is unable to be simply war, to be simply about killing, and instead turns itself into a grotesque infantile realityshow[.]"2 As the imagery turned upon itself, paradoxically, the sublime lost its effect. What was of most interest to me was not the images of torture and degradation, but instead the ontology of their making. They were made as souvenirs, personal documentation. E-mailed and let loose upon all of us for their horror. The military surely would have "contained" the images if possible. The "embedded" photographers and journalists would have never been able to publish such imagery, and it is unlikely that the military personnel would have behaved in such a manner with the "eyes" of the press upon them. The taking and distribution of these photographs is a testament to the hyperrreality of our age.

These images unraveled, at least temporarily, the war pornography with what at first glance seemed to be authentic imagery, providing a sense of realism that the bombs and screaming victims did not. With juxtapositions of laughter and tears seen in the Abu Ghirab photographs, we were able to see an internal conflict within ourselves. The media had failed in its singularity and questioning of the war,

\footnotetext{
${ }^{2}$ Jean Baudrillard, translated by Ames Hodges, The Conspiracy of Art: Manifestos, Interviews, Essays, edited by Sylvere Lotringer (New York, NY, 2005), 206.
} 
and what constituted "torture" ensued. However, I, as an artist, was affected. My work was no longer centered upon the contemporary sublime of mediated images, but instead was concerned with the ontology of the image in this digital age. What was it exactly that made these images so compelling? I remember that when I first saw them, the juxtapositions of the detainees and the guards seemed faked. They seemed like digitally pasted images. Perhaps, this was due to their incongruent nature. Also, the images lacked the slicked up aesthetics of Madison Avenue and the composed realism of war photocorrespondents like Robert Capa. They seemed kind of hokey, like a family snapshot of a modest tourist attraction. The human beings being humiliated were not "there." They were the "object" of mild interest.

The photographs, paradoxically, had a "handmade" quality, which led to their sense of authenticity. However, it is important to note that these images were not authentic expressions, but were rather indicative of the desensitization of the makers and the hyperreal. Through mediation, the hyperreality of the image became reinforced, and that which was intended to be a singular "object" was proliferated to the point of exhaustion. Baudrillard reflects this notion by stating that "the forms of popular media themselves are the site of indifference, they are what produce indifference."3 This indifference is a product of the mediation and oversaturation of the image. Shocking images such as the Abu Ghirab photographs quickly lack their original vigor and now seem outdated.

The ontology of the image in the digital age is not an easy one to disentangle. But with the Abu Ghirab images, an ontology can begin to be explored visually. First, there is a hyperrealism to these images due to their dissemination and mediation. Second, digital technology has democratized the image to the point of futility. Baudrillard stated, "There is no longer a need for 'embedded' journalists because soldiers themselves are immersed in the image - thanks to digital technology, the images are definitely integrated into the war. They don't represent it anymore; they involve neither distance, nor

\footnotetext{
${ }^{3}$ Jean Baudrillard, The Conspiracy of Art, 145.
} 
perception, nor judgment. They no longer belong to the order of representation, nor of information in a strict sense. And, suddenly, the question of whether it is necessary to produce, reproduce, broadcast, or prohibit them, or even the 'essential' question of how to know if they are true or false is 'irrelevant'.,4 Baudrillard seems to be implying here that images lack the ability to communicate with an amount of certitude, but are rather a product of digital code. Third, the "hand-made" element, the sense of beingthere through the awkwardness of the pose, provides a sense of reality for the image of the hyperrreal.

The idea that the Abu Ghirab images were "fakes" created through digital manipulations is paramount to my thinking about them and for revealing our relationship to digital technology today and image production. It provokes a kind of questioning that I want the work in this exhibition to provoke: "What makes an image an image?" This questioning may seem obtuse, but it is somewhat provocative. In a world of digital manipulation, authenticity of the photographic image, if there was ever such a thing, is revoked. Thus, the image has only aesthetic value, and if an image has only aesthetic value, do images convey meaning? Or are they empty expressions which provide, at best, entertainment, or at worst, a "transparent" ideology?

Baudrillard argued that hyperrealism is an "allegory of death," in that the repetition of the mediated image reinforces "its" own reality, divorcing it in a sense from the real. Baudrillard wrote, "From medium to medium the real is volatilized, becoming an allegory of death. But it is also in a sense, reinforced through its own destruction. It becomes reality for its own sake, the fetishism of the lost object: no longer the object of representation, but the ecstasy of denial and of its own ritual extermination: the hyperreal." ${ }^{, 5}$ This is certainly true of the Abu Ghirab images, but it is also true of countless images seen on the nightly news. Technology has also impacted the art world in perhaps a "deadly" way. Mediated images of "popular" works of art like those by Leonardo da Vinci, Monet and Warhol to name a few have all but lost the original meanings. These artists had profound insights and

\footnotetext{
${ }^{4}$ Ibid., 207.

5Jean Baudrillard, “The Hyper-realism of Simulation”, Art in Theory 1900-2000: An Anthology of Changing Ideas, edited by Charles Harrison and Paul Wood(Malden, MA: Blackwell Publishing, 2003), 1018.
} 
new methodologies of working, which have been eradicated, in part by time, but also by their proliferation and the various means of reproduction. Works by these artists can be purchased as "prints," posters, coffee cups, umbrellas and so on, making the work take on a solely aesthetic function and removing the original concerns and content of these artists and reducing their significance.

The works in this exhibition consist of both paintings and digital photographs: singular objects and works that exist in multiplicity. They are my attempt to tackle visually these problems that now exist in this hyperreal world, in which the viewer expects non-reality through mediated images. It seems absurd to say that images are not with meaning today, even in their state of hyperreality. They communicate, but is it that communication invalid, and if so, what does such communication do to us, the viewer? Do we become dismissive of the actual, the "real," world and allow these images to simply entertain us? My work attempts to reveal the means of mediation and force a "second look." Unlike Baudrillard, I do not believe that we are encased by hyperrreality, but rather that we live in a world that is increasingly hyperreal and juxtaposed with reality. As will be explained, the paintings and photographs in this exhibition, through their methodology and imagery, attempt to "reproduce" this juxtaposition of the real and the hyperreal. 


\section{Painting}

The objective of my recent paintings is to question the construction and ontology of imagery in the digital age, and how this has affected our expectations of perception. The information age has shifted human perception and the act of seeing from something based in reality to a perfection of that reality. As stated in the introduction, this is what Jean Baudrillard referred to as the hyperreal. My work is meant to deconstruct how computer programs heighten reality, making imagery "more real than real," and to investigate how our expectations of representations, which have become skewed by most mediated images toward a synthetic perfection, an idealism that enmeshes the real with a matrix of layered imagery. This layering produces a new kind of image. One that is no longer singular, no matter the medium due to mediation of the image, in which it is expected that the image prior to commercial printing, for example, is altered to some degree. The image is "freed" of "blemishes" and the color can be heightened. Digital technology has made image production and proliferation inexpensive. Without the time consuming processes of traditional color photography, nor even the need for the printed object with devices such as the Ipod, images are more prolific today than ever before. In many ways, we now live in a world dominated, not through the authority of the written word, but through the impact of the image as perfect and complete. What is even more amazing is that most of us do not expect images to have a true value. With our knowledge and integration of technology, this expectation is nullified.

Painting as a discipline has been challenged for many years and has been assumed to be dead, and yet painters still paint and people are still compelled to look. Painting, unlike photography, has long abandoned the idea of truth of image as being integral to a work of art. This abandonment of documenting accurately the world around us was ironically, it could be argued, initiated by photography. Photography, when invented in the $19^{\text {th }}$ century, was an analog process, a chemical one, a scientific one, which provided a "truthful" representation. Of course, this has been widely disputed, the photographer chooses the subject, angle, the lighting and so forth, but this misconception, this new 
technology, provided an opening in the history of painting for a different kind of truth to be explore by painters, a philosophical truth. In a recent conversation with Sylvere Lotringer, Paul Virilio noted this philosophical exploration, while discussing the impulse of philosophers to write of and about painters. Virilio states, "I've always said that [Marcel] Duchamp was a philosopher who painted."6 I would argue that this is true of all painters, including myself, but this becomes isolated with the invention of photography.

From Eduard Manet and Claude Monet in the $19^{\text {th }}$ century to Andy Warhol and Gerhard Richter in the $20^{\text {th }}$ and $21^{\text {st }}$ centuries, painters have been invested in the revelation of truth to greater or lesser degrees. Many contemporary painters, like Richter and Sigmar Polke have focused on photography and photographic representation as a subject of their work. The paintings in this exhibition are concerned with the methodology of digital processes from "capture" devices, like digital camcorders, cameras and scanners, to digital editing programs and the ways in which they have changed our perception of the world. Virilio argues that the word 'image' due to technology has become outdated, when he states, “The word 'image' is a portamanteau word: they put it into whatever they wanted, and in a certain way the word 'visual' is already better than the word 'image'. I say that we live in a civilization of the optical. It is optics that is at stake: the structure of the visual[.]"7 By viewing painting as "optical," as Virilio states, technology is not necessarily disparate to the analog of painting. Both create images. The difference is that I am not a machine, but I certainly am a maker of the optical, and like most everyone else I am a viewer of the optical being a part of this world.

Influenced by the reductive processes of $20^{\text {th }}$ century art from Piet Mondrian to Richter, my paintings are abstract. This abstraction affords a movement away, in part from the image itself, and places an emphasis upon process. The relationship between the photograph and the painting is one that

${ }^{6}$ Sylvere Lotringer and Paul Virilio, translated by Michael Taormina, The Accident of Art (New, NY: Semiotext(e), 2005) 68.

${ }^{7}$ Sylvere Lotringer and Paul Virilio, The Accident of Art, 69. 
has in many ways been a long concern of painters. However, the relationship of the painting to digital technology is one which is still being sorted today. Thus, the goal of the painting in this exhibition is, in part, to explore this relationship, which converges upon the optical, or the physical perception of the viewer. In order to reveal this relationship, I have attempted to deconstruct the digital process of editing programs like Photoshop, which synthesize layers of altered imagery to produce a finished product. By being reductive, the digital modality and physical act of painting begin to merge.

The support and medium is important to the works in order to convey a sense of history and contemporaneity. The works are constructed of oil paint on commercially cast acrylic sheets. All the paintings in the exhibition are composed of three sheets of this cast acrylic, which visually unify into a "singular" image. However, each layer is made physically distinct from the next through a system of polycarbonate nuts and bolts which forces the painting into a state of object-hood, emphasizing a minimalist sculptural quality. The physical engagement of the viewer is taken into consideration through this sculptural quality. As the viewer moves left to right of the image, each layer is slightly displaced, shifting with the viewer and placing the work in a state of flux. The length of the bolts is one and a half inches, which is comparable to the width of a stretcher bar, making an analogous relationship to a tradition oil on canvas painting.

The medium is also intended to force a questioning of what makes a painting a painting in the $21^{\text {st }}$ century. A recent article poses this question, exploring the works of contemporary painters whose process and media are irregular to the history of the art form. She writes, "Ours is the age of the hybrid, the cross-over, the many splendid thing, a time when the combined force of new-media, post-modern thought, and human history has made it impossible for artists to worship a single god of painting. Indeed, the practice of this ancient art may owe its continued health to its amazingly elastic nature."8 Hybridization occurs in these works through the medium of oil paint and its support of the cast

\footnotetext{
${ }^{8}$ Linda Yablonsky, “What Makes A Painting A Painting,” ARTnews 104, no.4 (April: 2005): 96.
} 
acrylic sheet. It is also achieved through the use of color and opacity. Each layer is painted red, blue or green. The color in the paintings is based upon the RGB (Red, Green, Blue) color model, used by electronic systems to create a broad array of colors. Each layer is either R, G or B and visually impacts the next creating a tentative gestalt based upon the viewer's location, in which additive and subtractive color theory collides. The level of opacity also shifts within each layer. In a sense, the use of color is again a way in which to allude to technology and more specifically to so-called color channels in visual editing programs. Through the use of the layers of transparent acrylic sheets, my paintings are intended to question the ontology of the image and the nature of painting in the digital age, in which images are in a state of flux and are often intended to be democratic through the medium of technology.

The specific imagery is derived from synthetic and living plants. A modularity of the forms is created through abstraction, which is produced through an emphasis upon the contour line and a manipulation of that contour line, mimicking the digital process, and most specifically reduction. For me, perhaps the most striking feature of programs like Photoshop is, not simply the ability to work in multiple layers of imagery, but rather the tendency to reduce and abstract imagery to create a composite image. The reductivist aspect of my work borrows both from the history of $20^{\text {th }}$-century Modernism and technology.

The imagery is obtained either through the digital scan of the living plant, which in all the works in the exhibition is a rose clipping, or the digital photograph of a synthetic plant. Both are reduced to their contour line, becoming a silhouette which lacks the internal details of the original source, which is then transferred by hand onto $8 \frac{1 / 2}{2} 11$ inch window decal sheets. Modularity is achieved by layering these forms together to make a larger form. In all of the paintings in the exhibition, the first layer of the painting is composed of the contours of the rose clipping, and the second layer is composed of the modular forms derived from the synthetic plant. For post-structural deconstructivist philosophers, like Jacques Derrida (1930-2004), the contour becomes a boundary of 
linguistic signification, which contains and separates, creating a binary of meaning. That is, it becomes the point of recognition and ultimately mediation. Derrida states, "The outline (design or melodic line) is not only what permits imitation and the recognition of the represented in the representer. It is the element of formal difference which permits the contents (colored and sonorous substance) to appear. By the same token, it cannot give rise to [literally provide space for] art (techne) as memesis without constituting it forthwith as a technique of imitation. If art lives from an originary reproduction the art lives from this reproduction[.]" ${ }^{\prime 9}$ Thus, Derrida demonstrates that the outline is necessary for the creation of art, which from his point of view is Aristotelian by design being based upon memesis. I would add that it is this impulse to duplicate from Western artistic origins of the Ancient Greeks that in part has led to the optics of hyperreality today.

In $R B G$ (small), figure 1, these ideas and procedures become clearer. The first layer, the one nearest the viewer, is composed of large organic shapes of the scanned rose clippings produced by the negative space left after the window decal has been removed. The color of this layer is red, with a shifting opacity produced by the addition of white to the palette. The paint application varies, but is for the most part aggressively applied. Behind this layer is the second layer, which is painted blue. In this case, no white has been used and the paint is more or less evenly applied. Negative shapes arise from the synthetic plant in the areas where the decal had been placed. What is interesting is how the eye perceives these spaces left behind from the removal of the decals on both the first and second layers of the painting.

The third layer informs the first two. Pushing forward and becoming optically, but not physically, the first layer. The third layer in $R B G$ (small) is a semi-transparent green and is produced without the use of the window decals. Window decals are not used on this layer for any of the paintings

\footnotetext{
' Jacques Derrida,'The Exorbitant Question of Method' and 'The Engraving and Ambiguities of Formalism', from Of Grammatology, Art in Theory 1900-2000: An Anthology of Changing Ideas, edited by Charles Harrison and Paul Wood (Malden, MA: Blackwell Publishing, 2003), 948.
} 
in the exhibition, and it is important to note that colors of the layers shift from work to work. The process is the same for the third layer for all the paintings in the exhibition. It is made by applying the paint in a viscous manner. The paint is then removed by placing clear plastic over the sheet of cast acrylic, allowing it to partially adhere, and then removing the sheet. This is repeated until the desired effects are achieved. The process used for layer three is the most spontaneous. This spontaneity creates an organic effect, which serves as a unifying element in this and all the other paintings in the exhibition.

Absence plays a critical role in the works. It is in this negative space that positive forms emerge optically. The third layer, with its spontaneity, becomes the texture for the second and the same is true of layer two's relationship with layer one. The three layers blend and merge visually creating a temporary gestalt as the viewer moves before the painting. However, the layers become displaced, reinforcing the physicality of the work and the viewer's relationship to it. The removal, which creates this absence, is intended to allude to the distancing which occurs from the hyperreal, as does the means by which the imagery is obtained, with the scanned roses being more immediate than the photographed synthetic plant. The role of the oil paint, particularly that of the gutturally applied red layer of $R B G$ (small), which is applied with thick gestural passages using a palette knife and brush, is the most immediate, demonstrating the use of the hand and thus the appearance of humanity in the work, which makes the paint paramount in this relationship of hyperreality to the real, or the immaterial to the material.

The plant or flower as a subject is certainly not new in the history of art. It is one, however, that has often had a pejorative association as simply being decorative. During the $17^{\text {th }}$ century, flower painting became quite popular in the Netherlands. Artists, such as Rachel Ruysch (1664-1750), figure 2, gained celebrity and prestige for paintings of this "pejorative" subject. The Netherlands at this time had recently expelled its Spanish overlords and the institution of the Catholic Church was becoming the 
first democratic republic without feudal ties. Flower painting was seen as democratic and accessible. One did not need an education to be able to appreciate the formal beauty. In this way the subject appeals to me and seems to be germinal to the ideas of democracy associated with technology today. Morphologically speaking, flowers and plants have specific structures which appear to have an internal modularity, repeatable units, which could be why they have been a favored subject in the history of abstraction, but is also how they relate to computer technology. Andy Warhol (1928-87) was perhaps the first to recognize this parallel with his Flower painting from the 1960s. It was created not by hand, but through the use of technology with photo-silkscreen techniques. Warhol's flowers, figure 3, reveal the technology of the industrial age of which he was a product.

Rudolf Stingel (1956) continues this exploration of the relationship of technology and perception of the natural world with his two untitled works, figure 4 and 5 , that were on exhibit at the 2008 Carnegie International, in which a modular field of flowers upon a ground of gold is extended in space through the use of linear perspective. The flowers are clearly artificial, yet through the use of perspective the viewer is compelled to "believe" in them and conceptually enters this constructed reality. Moreover this "reality" is a product of the hyper-real and is preferenced for its perfection over the natural forms represented.

Another artist whose work seems to be engaging the hyperreality of the digitized image is Robert Kushner (b.1949) established as member of the Pattern and Decoration movement of the 1980s. Kushner's current work, such as Morning Glories II, 2007, figure 6, seems more related to Stingel's work than to his affiliates of the 1970s. The grid functions as a stabilizing element in this work in which the floral imagery has been abstracted in various ways. The juxtaposition of the organic and the inorganic in this work suggests a dialog between the natural and the artificial, which is heightened by the intense color palette used by the artist.

My current work, with its commonalities of subject and ideology, differs greatly with the last 
three mentioned artists, largely due to my choice of materials. Rather than working upon conventional supports like Kushner, Stingel or Warhol, I have opted to work on transparent acrylic sheets, which force a physicality to the layers of my imagery instead of compressing these layers into a single twodimensional image. The layers are pulled apart, and this places them in a state of objecthood and flux as the viewer engages the work. They are also intended to be a direct referent to digital image modification. In recent work, the conceptual artist Joseph Kosuth (b.1945) has also showed an interest in deconstructing meaning through the the proliferation of an image, in which the layers are made physical and in conflict with one another. With No Number \#3, figure 7, 1990, Kosuth utilizes the same text silkscreened onto three glass panels, through which a visual disruption of the text occurs obliterating its original meaning. The work dates to 1990 and clearly seems to be addressing issues of meaning in the age of digital proliferation.

Visual proliferation is also a preoccupation of the painter/artist Diana Cooper (b. 1964) who works with a variety of media, including transparent acetate, figures 8 and 9. Regarding her imagery, Cooper states, "Digital, biological and medical systems are our life support systems but they can fail us too. In their complexity they become unstable and sometimes quite fragile. Fragility is important to me because it underscores our own vulnerability." ${ }^{10}$ For Cooper, attempting to understand and deconstruct the systems that bind society is an important concern. For me, this interest is centered upon image construction within our society, and how it mediates meaning. The ontology of the image is my concern, and how this technology is forcing a question of what defines a painting as a painting within this environment. Cooper also expresses this concern when she states, "What determines what a painting is?"11 It is this sort of questioning that I want my work to invoke.

A questioning of what determines a painting is also raised by painter Olivia Booth ${ }^{12}$ whose acrylic paintings are on single sheets of glass, figures 10 and 11 . The imagery is unrecognizable,

\footnotetext{
${ }^{10}$ Diana Cooper, www.dianacooper.net, Accessed on April 25, 2009.

${ }^{11}$ Diana Cooper, www.dianacooper.net, Accessed on April 25, 2009.

${ }^{12}$ Olivia Booth received her M.F.A. from the Art Center College of Design, Pasadena, CA in 2003.
} 
abstract and minimal in form and color. Like my paintings, these works question the objecthood of a painting with the use of light. When lit in a gallery setting, the imagery of the painting is projected onto the wall creating a duplicity: one image physical, the other immaterial. There is a greater complexity of forms, which is generated through the use of three layers of imagery. Each layer, however, visually impacts the next creating a tentative gestalt based upon the viewer's location, in which, like Booth's paintings, additive and subtractive color merge, and under gallery lighting, similar effects occur. Through the use of digitally captured floral imagery and layers of transparent acrylic, my paintings are intended to question the ontology of the image and the nature of painting in the digital age, in which images are in a state of flux and are intended to be democratic. 


\section{Photography}

The photographic work in the exhibition, like my painting, is similarly concerned with a questioning of contemporary image construction and the ontology of the image today. However, the emphasis is placed upon the hyperreality of the photograph itself as it exhibits a plausible truth of reality to the viewer. To do this, I integrate both imagery from reality and fabricated objects, which, within the context of the real take on a connotation of reality. This integration forces a displacement upon the photographic image produced. The result is an image that pushes further the boundaries of the real and the constructed, integrating the two into an almost seamless unity, necessitating a second look and revealing the tell of the constructed from "the real." The photographs presented here are divided into two distinct, but interrelated series. The first is based upon floral imagery and the second is based upon the ephemeral nature of the sky.

For the first series, I began engaging the floral imagery used in my paintings, most specifically, the rose. I purchased synthetic roses. I chose to purchase the inexpensive synthetic, rather than the expensive ones, in order to reveal the artificiality through its crude craftsmanship. The imagery was derived by attaching synthetic roses onto a living rosebush. Upon close inspection the full blooms of the synthetic roses are clearly out of season for the rosebush. The entropic qualities of the living plant contrast against the synthetic, perfect, flowers, making the resulting photographs seem almost miraculous, 'more real than real', hyperreal. The leaves of the rosebush reveal an imperfection, disease. A seasoned gardener or botanist would be able to identify this as a fungal infestation known as "blackspot." With aspects of both time and disease informing the image, the closely inspecting viewer starts to question the authenticity of the work itself. As stated earlier, the synthetic flowers, purposefully chosen for their crude qualities, "reveal" themselves as artificial through the regularity of the cast and through the frayed edges in which bare threads are seen by the viewer. This reinforces this questioning of the authenticity of the photograph and the initial expectation of truth in the work. 
Examining two photographs from the exhibition, the aspect of time and authenticity become more clear. Both Synthetic Flower (Day), figure 12, and Synthetic Flower (Night), figure 13, depict close-ups of the synthetic roses placed upon the rosebush. Looking closely, the strange woven texture of the flowers is seen, as well as bare threads of the polyester frayed edges of the petals. The stems of the living plant are somewhat bare and the leaves reveal the "blackspot." These two elements contrast sharply with the vivid color of the synthetic roses, revealing the construction of the work. At first glance, the photographs appear perfect, maybe too perfect. This perfection may be questioned. With digital technology and its prolific application, many of us may suspect that the color has been altered, or rather enhanced digitally. Even after close inspection, this may still be a question, one which cannot be fully known, but what is revealed is the handmade aspect of the photograph itself, in terms of its physical construction. This handmade aspect provides, in part, the initial sense of authenticity in the work.

The expectation and surprise seen in these works is described in the post-structuralist philosopher Roland Barthes' (1915-1980) last book, Camera Lucinda (1980), in which he discusses, in part, two ways in which we take interest in photography: the studium and the punctum. As Margaret Iversen succinctly explains, "The generalized interest, pleasure, or concern a photograph gives us indicates its possession of a studium. Photographs with a studium we judge as "good." But in some photographs there also lurks a detail, a punctum, which takes the viewer by surprise. It "pricks" him or her and completely alters the sense of the image." ${ }^{13}$ In these works I have purposefully intended to engage both the studium and the punctum. The images of the flowers are indeed pejorative. They are intended to register as somewhere between calendar art and "crafted" photography. Democratic imagery that would be more likely to be seen hanging in an average person's house as "wall art," than

\footnotetext{
${ }^{13}$ Margaret Iversen, Beyond Pleasure: Freud, Lacan Barthes (University Park, PA: The Pennsylvania State University Press, 2007), 121.
} 
in the gallery space of a white cube. This is meant to question the idea of "good" photography. Although artists like Larry Clark (b. 1943) or Gregory Crewdson (b. 1962) produce fine art photography, I would be extremely surprised to find it in anyone's home that I know. This assumption of "good" is then challenged by the punctum of the bare threads and sickly plant, which reveals the artifice of the image and hopefully "pricks" the viewer jarring them and forcing he or she to question the image and ultimately question the hyperreality of the world in which we live.

For the second series of images in the exhibition, I photographed a reflected image of the sky using a mirror. Placed upon this mirror were cloud forms made of cotton batting. The resulting images placed the cotton batting, the "cloud," into the sky, and due to its new context, the viewer is temporarily "tricked," as with the floral photographs, into believing it is an actual cloud. With the two photographs in the exhibition, Cotton Cloud 1 and Cotton Cloud 2, figures 14 and 15, the same constructed cloud is seen in two places at once, which is intended to force a comparison. This was achieved simply by changing my point of view as I photographed the image. As in the painting in the exhibition, my physical displacement altered the image.

The fabricated clouds are intended to be preferred by the viewer, because the "cloud" conforms more to the conception of what a cloud should look like than the ever changing actual form. In this situation, Jean Baudrillard's concept of the hyperreal is as being, in part, defined by a preference for things beyond the real, the 'more real than real', the perfected, the thing that conforms to our expectation of the thing over the thing itself. For Baudrillard, Disneyland is the epitome of the hyperreal, in that it provides a perfected reality, one in which our preconceptions of things are reinforced through an idealized world, in which the nature of reality is not questioned, but preferred. This also relates to Derrida's notion of the contour as the point of visual recognition, and is meant to reference the childhood activity of making clouds out of cotton balls and affixing them with glue onto 
paper, a childhood activity that encourages simplification to the contour. After all, a cloud is essentially formless, being in a constant state of flux, and yet we have a conception of its shape.

Today, the hyperreal seems to be fully integrated, perhaps due to socialization, into our perception of reality. Women's make-up is now fashioned to emulate the airbrushing that occurs through Photoshop, when depicting fashion models on the covers of magazines. Fur-real Pets produces a line of robotic toys for children that realistically emulate the actions, sounds and behaviors of many different animals, ranging from parrots to ponies. Synthetic plants are often so realistic that they are easily mistaken for living ones. So much so that touching the leaf is not necessarily proof enough. I myself have be known to "dig" into the pot to see if it is in dirt, as if that would determine its origin. Technology has been instrumental in, not only the construction of the hyperreal, but our willingness to accept it, creating a plausible synthesis of reality and the fictitious.

This disconnect is demonstrated in the work of Hiroshi Sugimoto (b. 1948) particularly with his photographs of wax figures from the London Royal Portrait gallery of well known aristocrats. His image of Henry VIII, figure 16, provides the viewer with a similar plausibility of reality. The historicism of the work, being derived from the $16^{\text {th }}$ century painting by Hans Holbein the Younger, makes Sugimoto's image alarming. The image has a plausibility of being taken from life, but it clearly could not have been so. Janet Koplos notes that "the technology of the modern era tricks us into regarding them as contemporary people," like "someone you'd pass on the street rather than a historical figure[.]"14 This metaphysical paradox jars the viewer into a questioning of the photograph. Furthermore, even though the photograph provides a convincing likeness, it lacks life. The viewer senses the unnatural stillness of the subject, its breathlessness. My "clouds" and "flowers" too seem to have this sort of stillness, when juxtaposed to actual sky or upon a living rosebush, and not unlike

\footnotetext{
${ }^{14}$ Janet Koplos, “Portraits of Light,” Art in America , vol.2(February:2006): 88.
} 
Sugimoto, it is my objective for my images of "clouds" and "flowers" to question the nature and construction of the photographic image.

Another artist who literally constructs his imagery to create a plausible reality is Thomas Demand (b. 1964). Demand often seeks out his imagery of interiors in popular magazines and reconstructs the image on a miniature scale using cardboard and paint. After which, he photographs, figure 17, the model to resemble its source from the magazine, often employing the same angle and lighting of the appropriated photograph. Initially, Demand's resulting image appears flawless with its flat planes of color and visual organization. It also has an unnatural quality. Although the spaces seem to be capable of accommodating human presence, they are strangely vacant. This is when his tells of construction begin to be perceived: the edge of a cardboard form, a streak of paint, the irregularity of a circle or square. Suddenly, the viewer is aware that this perfected space is constructed, a hyperreal space, one in which Baudrillard's simulacrum is tested. Although I employ Photoshop to aid in the synthesis of the sky and the "cloud," the texture after close inspection seems odd, fibrous, and the lighting artificial. The same is true of the "flowers" with their bare threads and patterned surface. Soon the viewer, through these tells, is able to discern the artifice of the image, which facilitates a questioning, not only of the individual image, but hopefully of that of the image today, and is intended to force him/her to question the authenticity of the photograph entirely, and by extension his or her perception of the world. 


\section{$\underline{\text { Conclusion }}$}

The relationship between the paintings and the photographs in the exhibition is at first glance ambiguous. The reason for this ambiguity is, in part, due to the aesthetic relationship of one to the other. The paintings are abstract and somewhat untraditional due to their supports (clear acrylic sheets); the photographs have a "traditional" modality, being, ironically, digitally printed. Furthermore, the photographs are representational. Both, however, share a subject of the landscape and floral imagery. This ambiguity forces a questioning of the relationship between the two mediums: the painting and the photography. This is an aspect of the work that is intended to engage the viewer conceptually.

As one engages the paintings, the physical structure of the work becomes paramount to the work itself. The color is indicative of the RGB color mode, with each layer containing only one of these colors. The imagery is made through negation by removing the forms and creating a clear space for the other layers to fill, much like a copy and paste function in an image editing program. In contrast, the photographs seem to have been heightened in a visual editing program. The colors of the "roses" are vibrant and rich. The "clouds" have a strange sense of space due to the objecthood of the cotton batting being placed upon the mirror and the sky being reflected. This pushes the "cloud" toward the viewer visually in photograph. Upon closer inspection, it becomes clear that these aspects of the photographs have been physically placed there. The "roses" are synthetic, and this artificiality is demonstrated with the frayed edges. The "clouds" are also "artificial" and fibrous, due to the use of cotton batting to construct them. The works, both the paintings and the photographs, through the physical processes that make them, paradoxically engage the hypereality of the world we live in.

The work in the exhibition is meant to question our physical relationship with the hyperreal and Baudrillard's assertion that "today reality is itself is hyperrealist." 15 Today, it is certainly true that hyperreality encroaches upon our daily lives as never before. We seem to go in and out of the hyperreal

\footnotetext{
${ }^{15}$ Jean Baudrillard, Symbolic Exchange and Death, 456.
} 
state via cell phones, computers and other digital objects which serve an almost prosthetic function. Baudrillard's statement removes an essential element of humanity: free will; yet, we willingly engage these activities, and perhaps it is true that we do so more and more as technology becomes more expedient and easily accessible.

The works in the exhibition are an attempt to deconstruct the hyperreality of the visual image. I have attempted to do so by making a 'simulation' of the hyperreal, and purposefully disrupting it with the use of the hand in all of the works. None of these works are 'more real than the real'. Actually, it could be stated that their removal from reality is clearly evident through the 'imperfections' seen in the works, which assert their physical presence in the world, but also through their context as works of art position them in the realm of artifice. 


\section{$\underline{\text { Illustrations }}$}

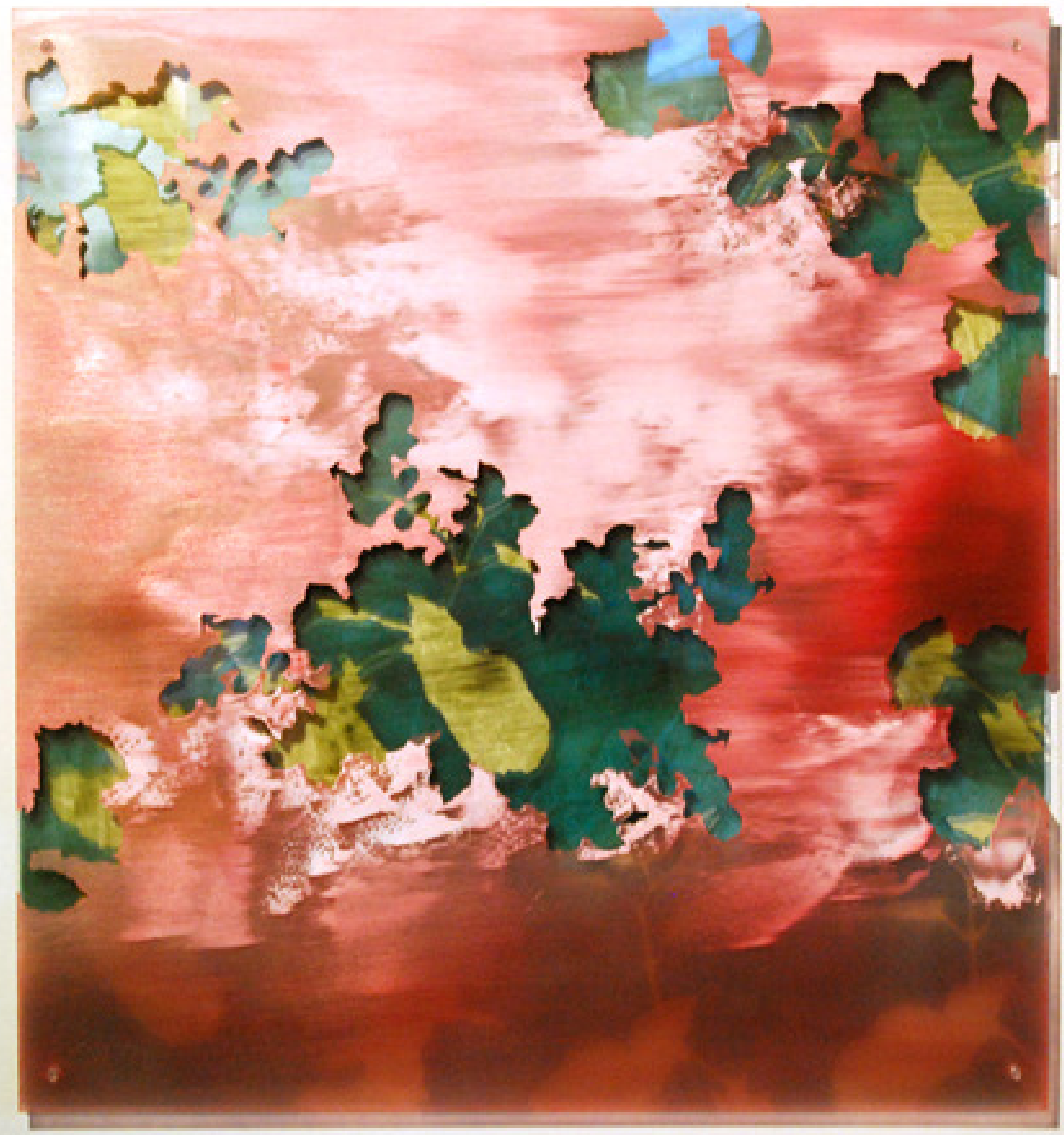

Figure 1: RBG (small), oil on three clear acrylic sheets with clear polycarbonate nuts and bolts, 2009. 


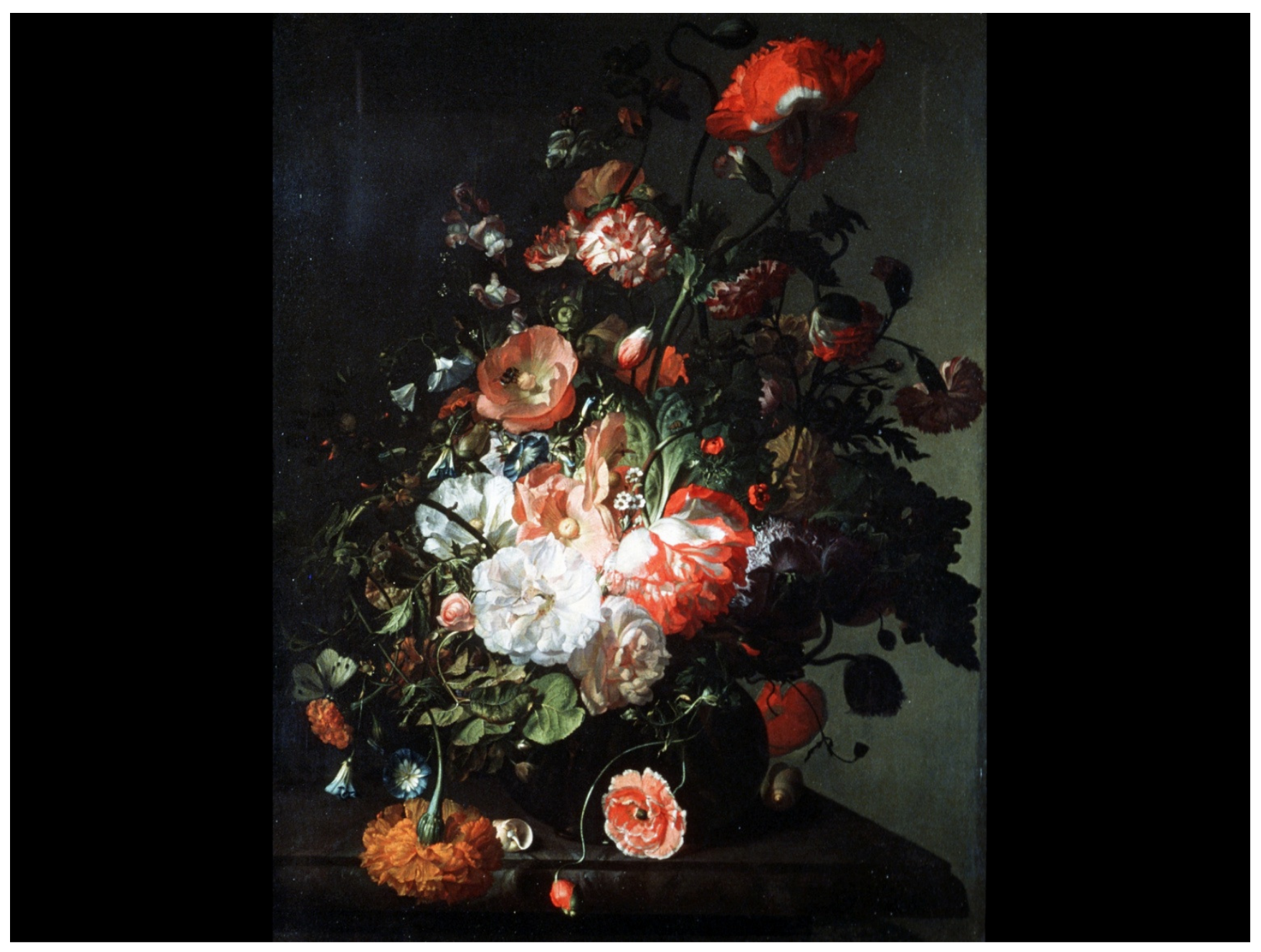

Figure 2: Rachel Ruysch, Flower Still Life, oil on canvas, 1703. 


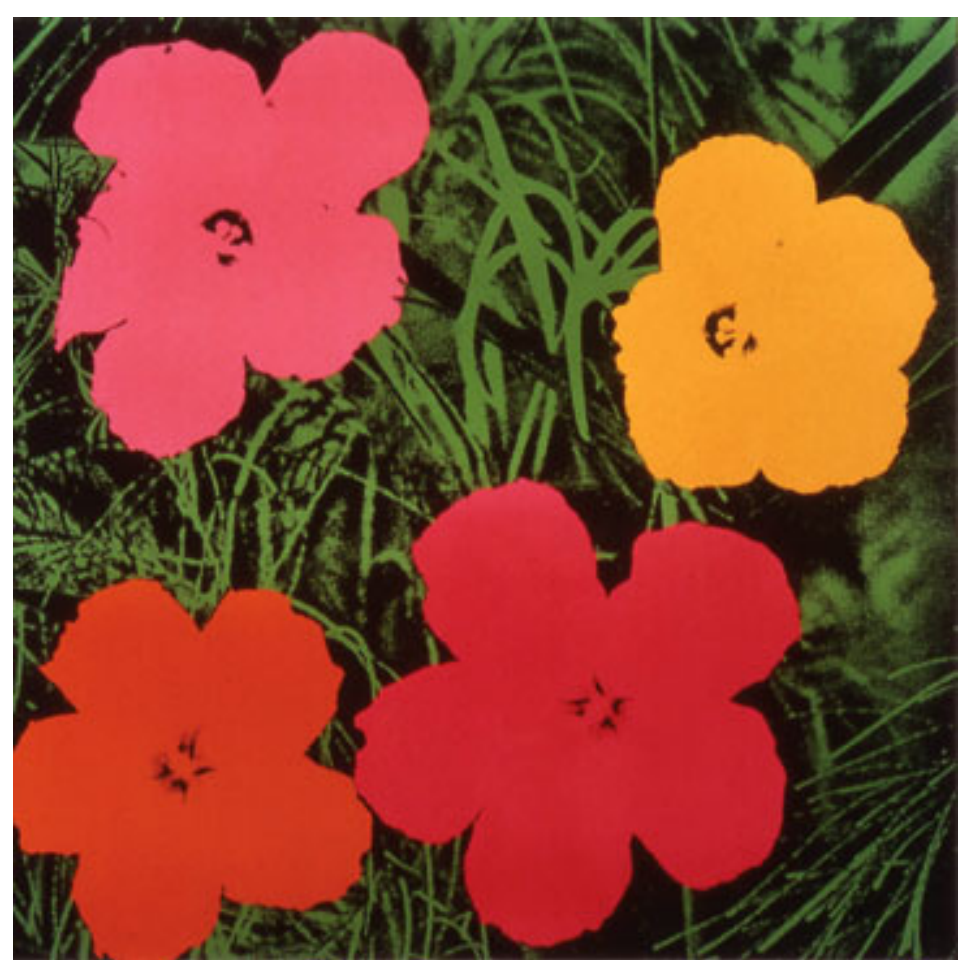

Figure 3: Andy Warhol, Flowers, 1964. 


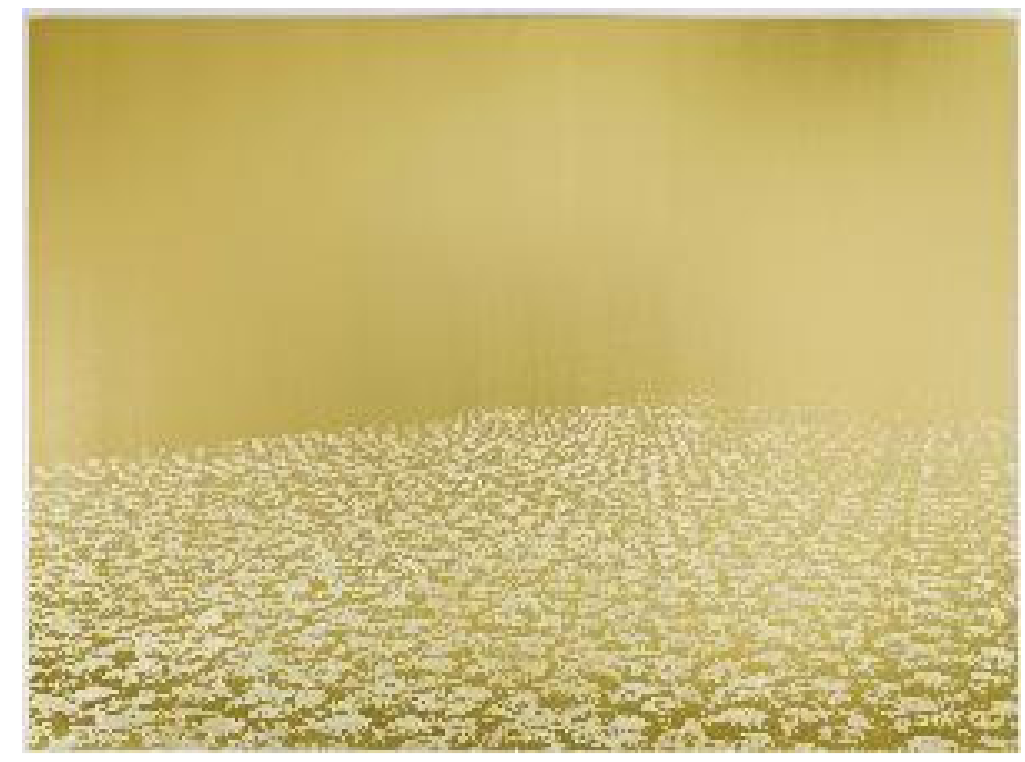

Figure 4: Rudolf Stingel, Untitled 1, 2008.

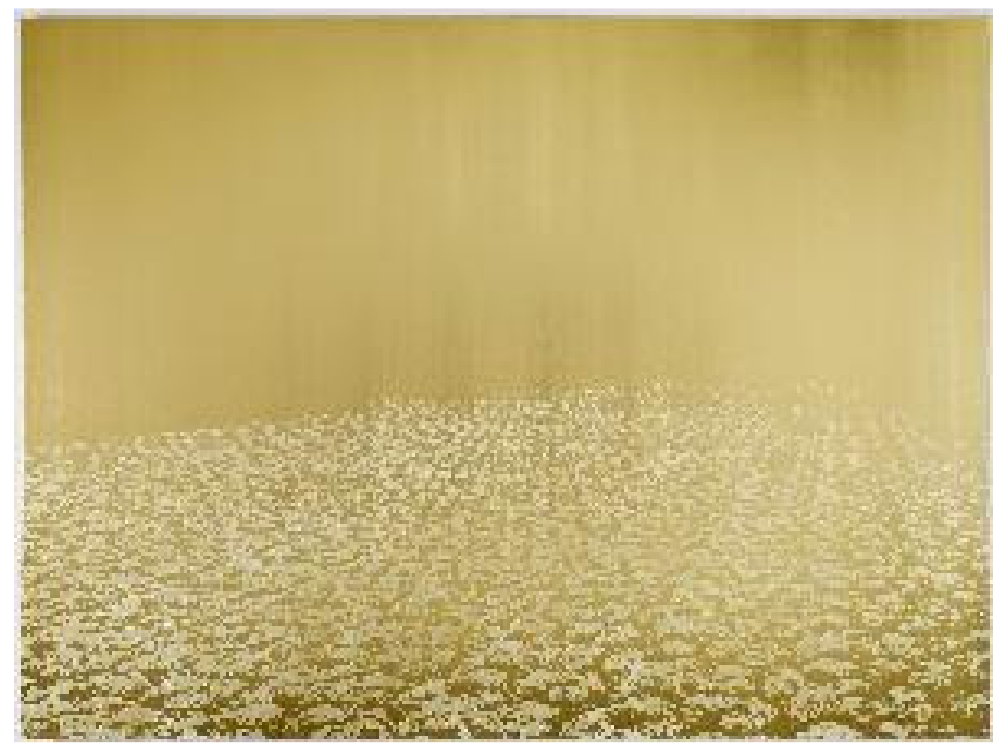

Figure 5: Rudolf Stingel, Untitled 2, 2008. 


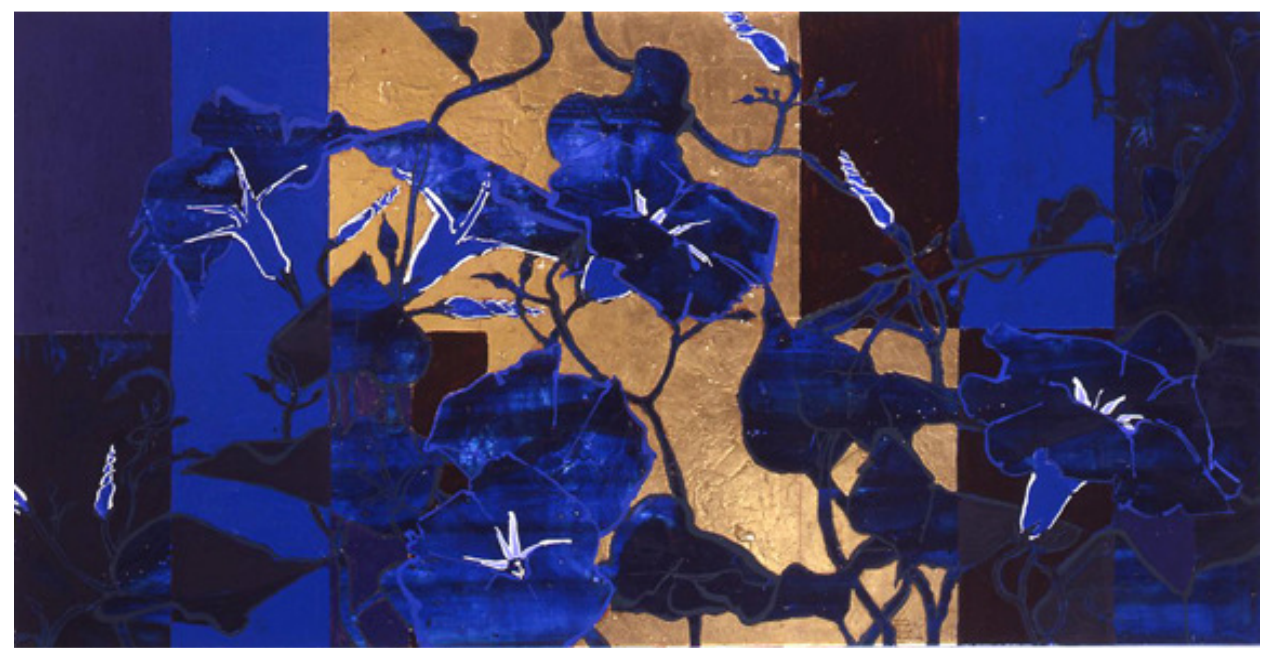

Figure 6: Robert Kushner, Morning Glories II, 2007. 


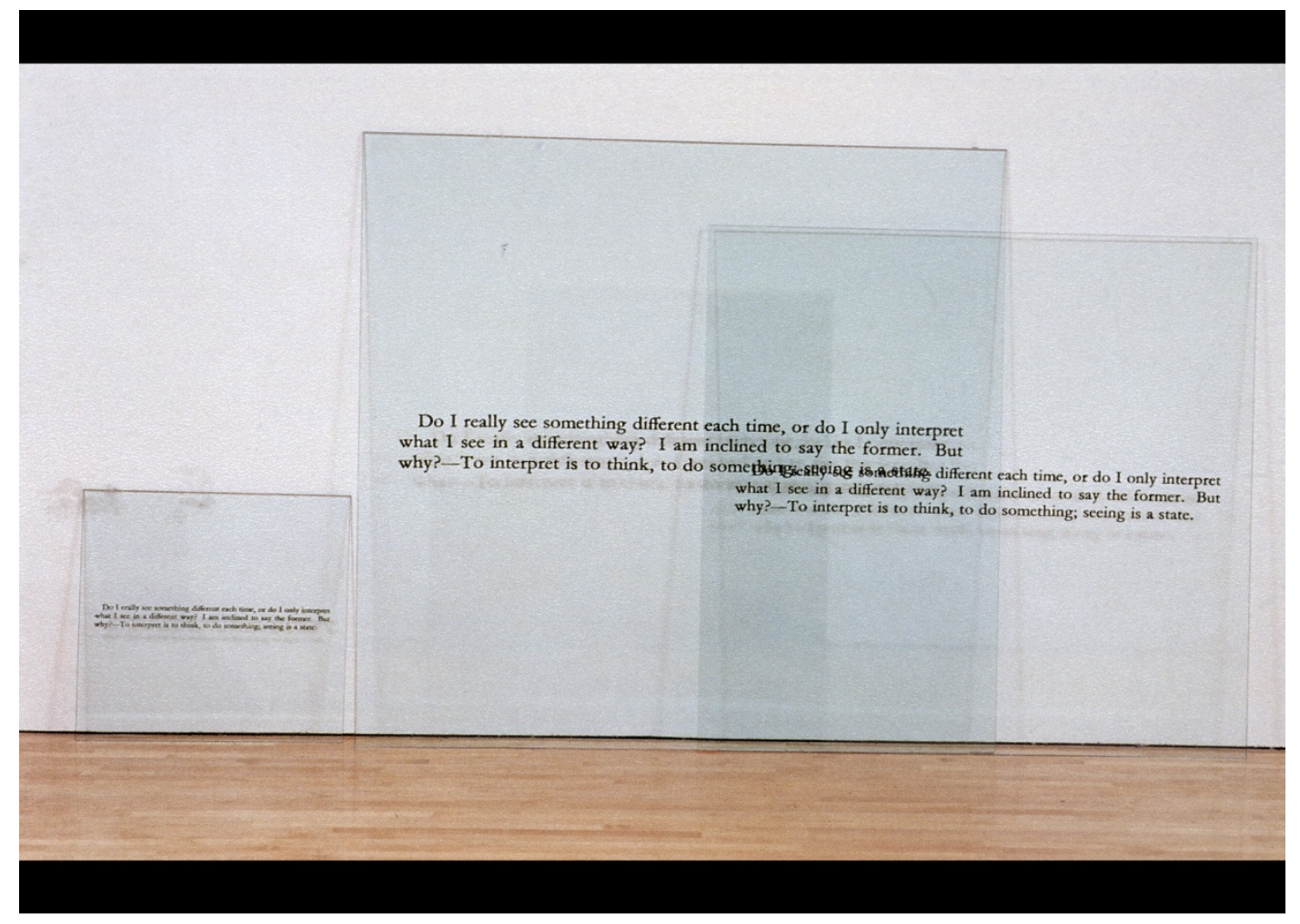

Figure 7: Joseph Kosuth, No Number \#3, 1990. 


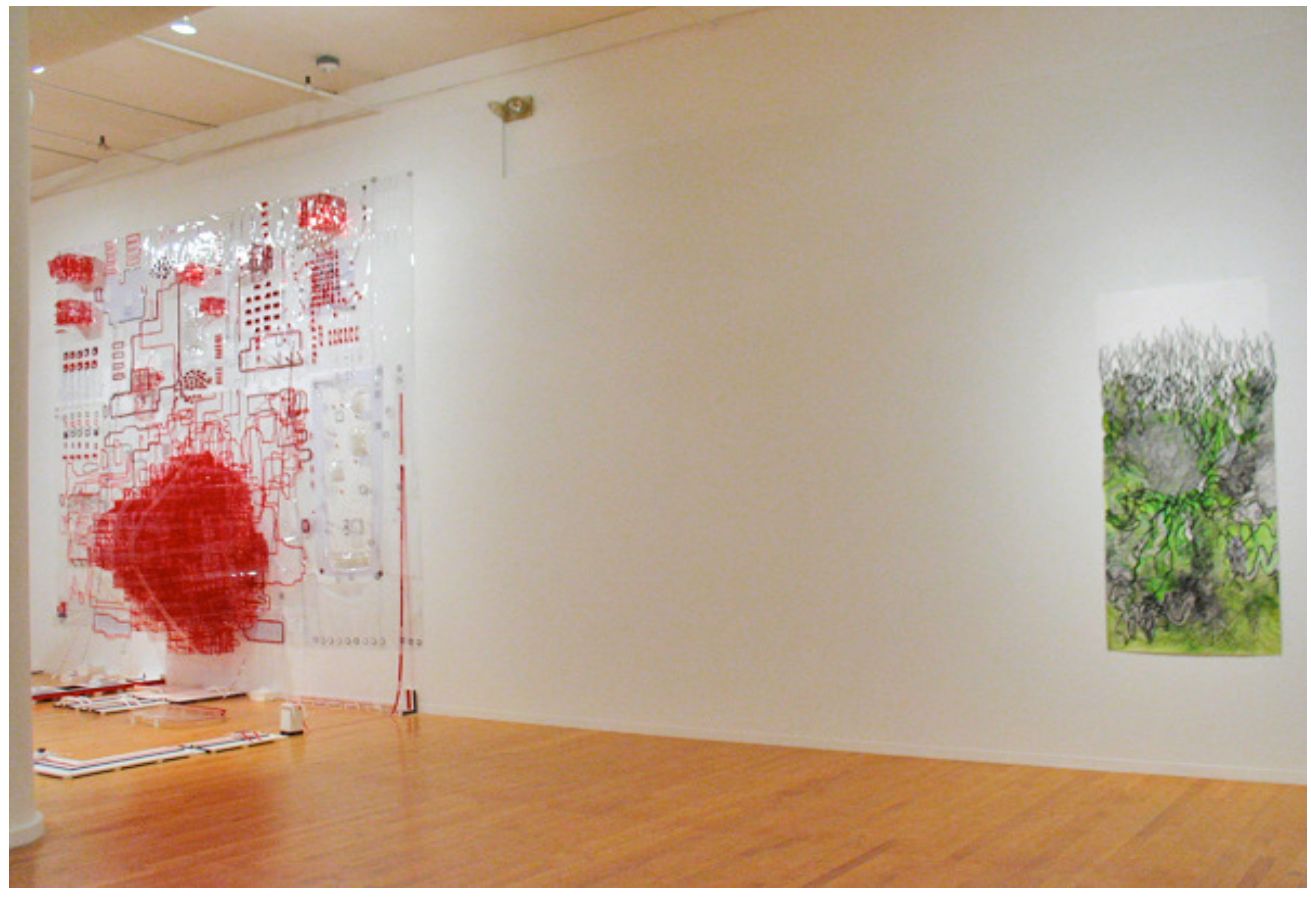

Figure 8: Diana Cooper, Beyond the Line: The Art of Diana Cooper, MOCA Cleveland, 2007.

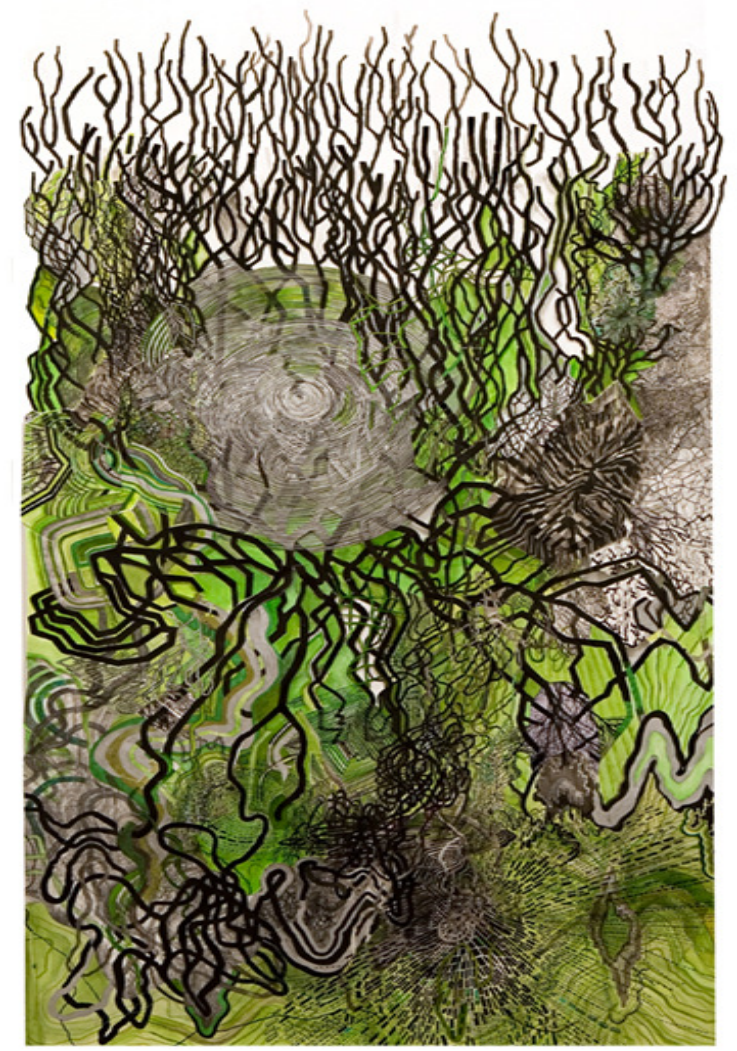

Figure 9: Diana Cooper, Daphne, Mixed Media, 2007. 


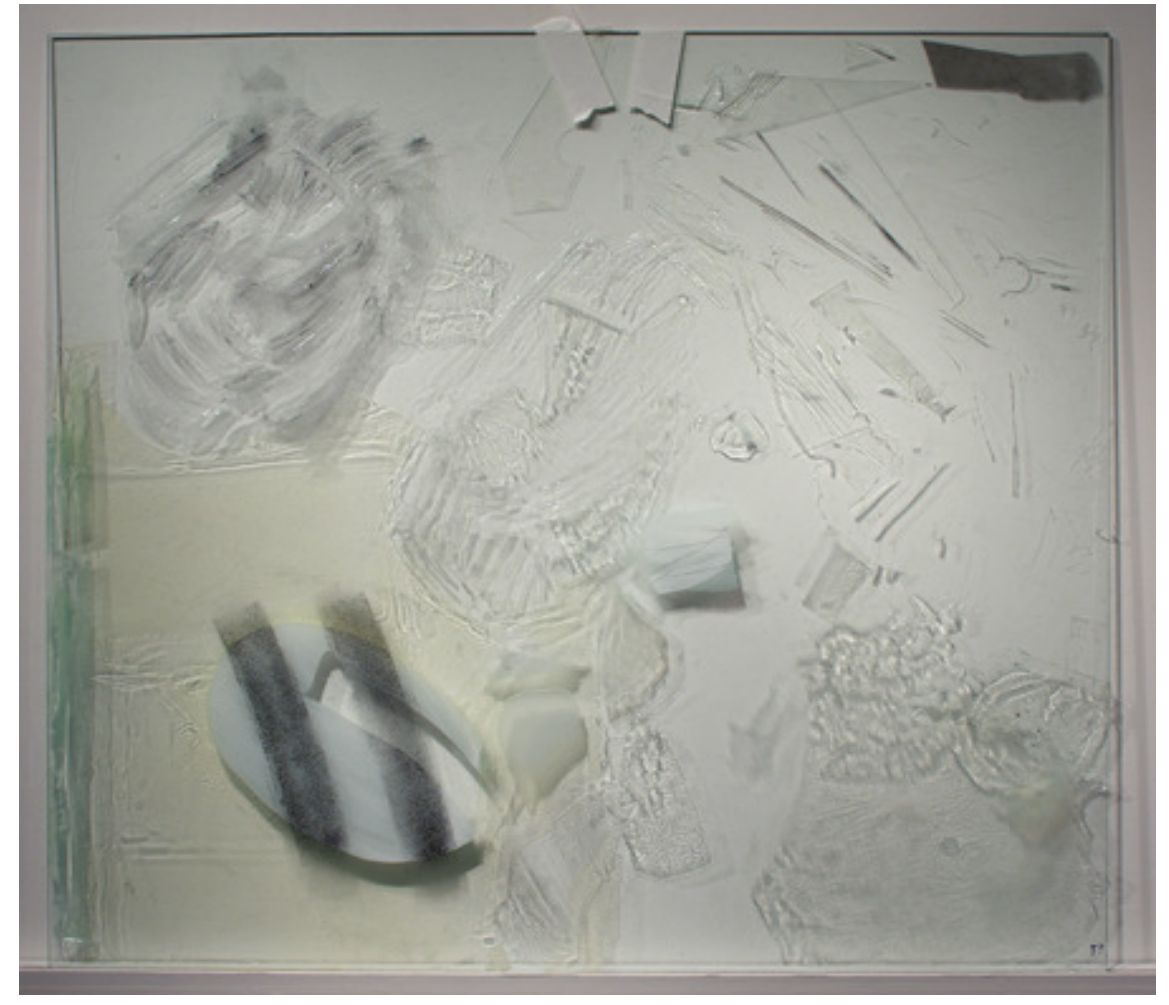

Figure 10: Olivia Booth, Outcast Piece, Acrylic on Glass, 200-2005. 


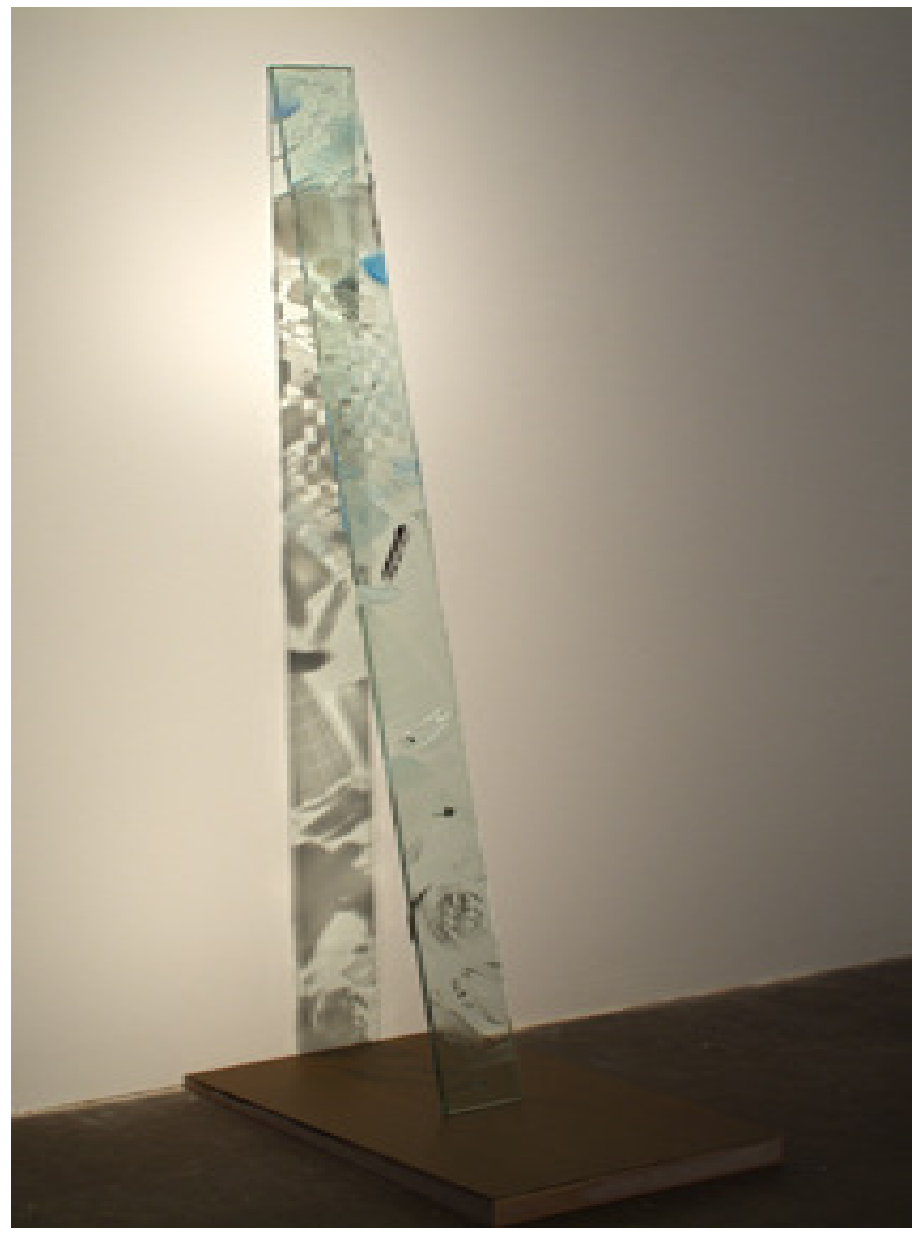

Figure 11: Olivia Booth Piranesi's Gimbles, Acrylic on glass, wood stand, 2005. 


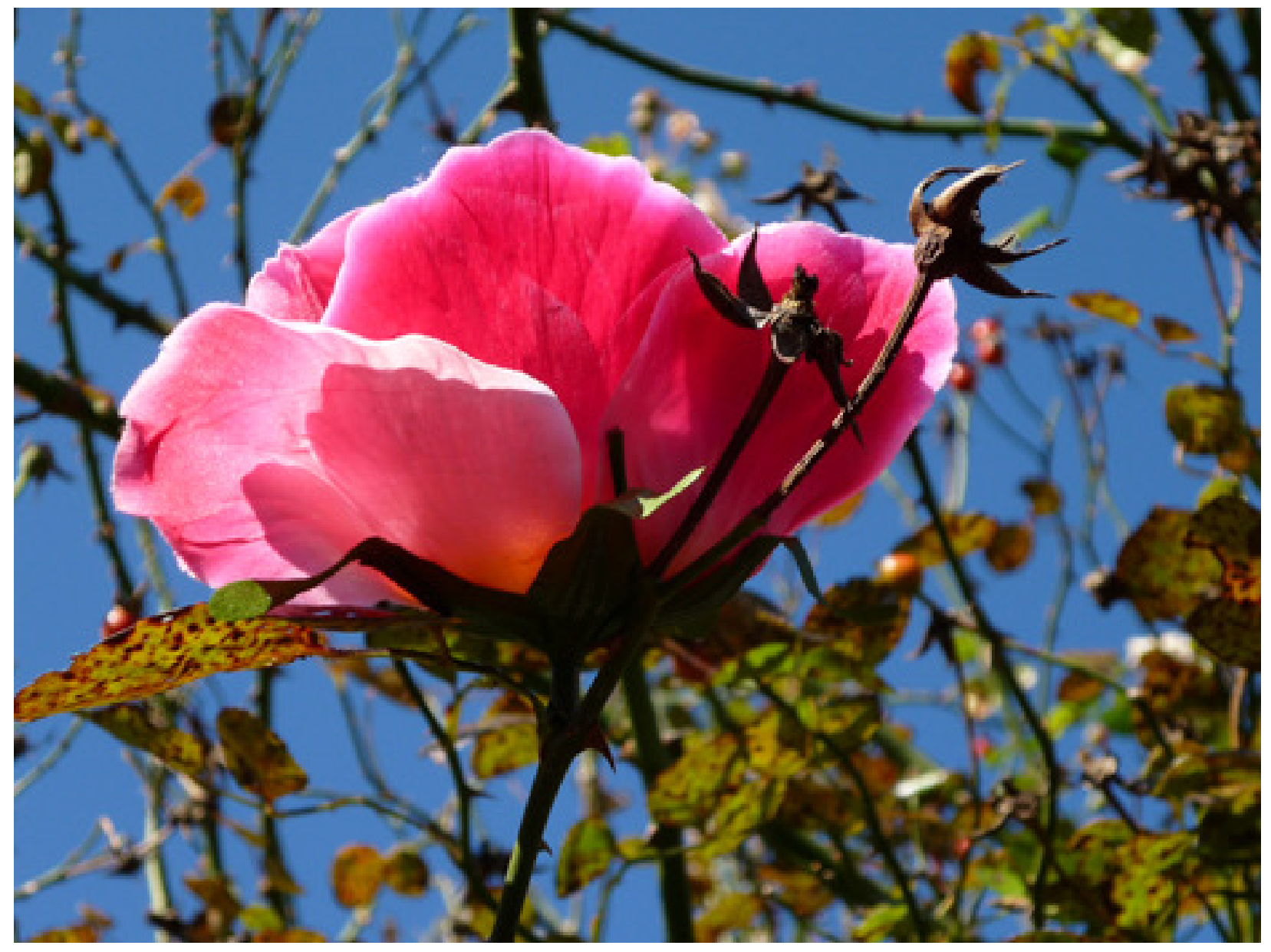

Figure 12: Synthetic Flower (Day), Ink Jet Print, 18 x 24 inches, 2009. 


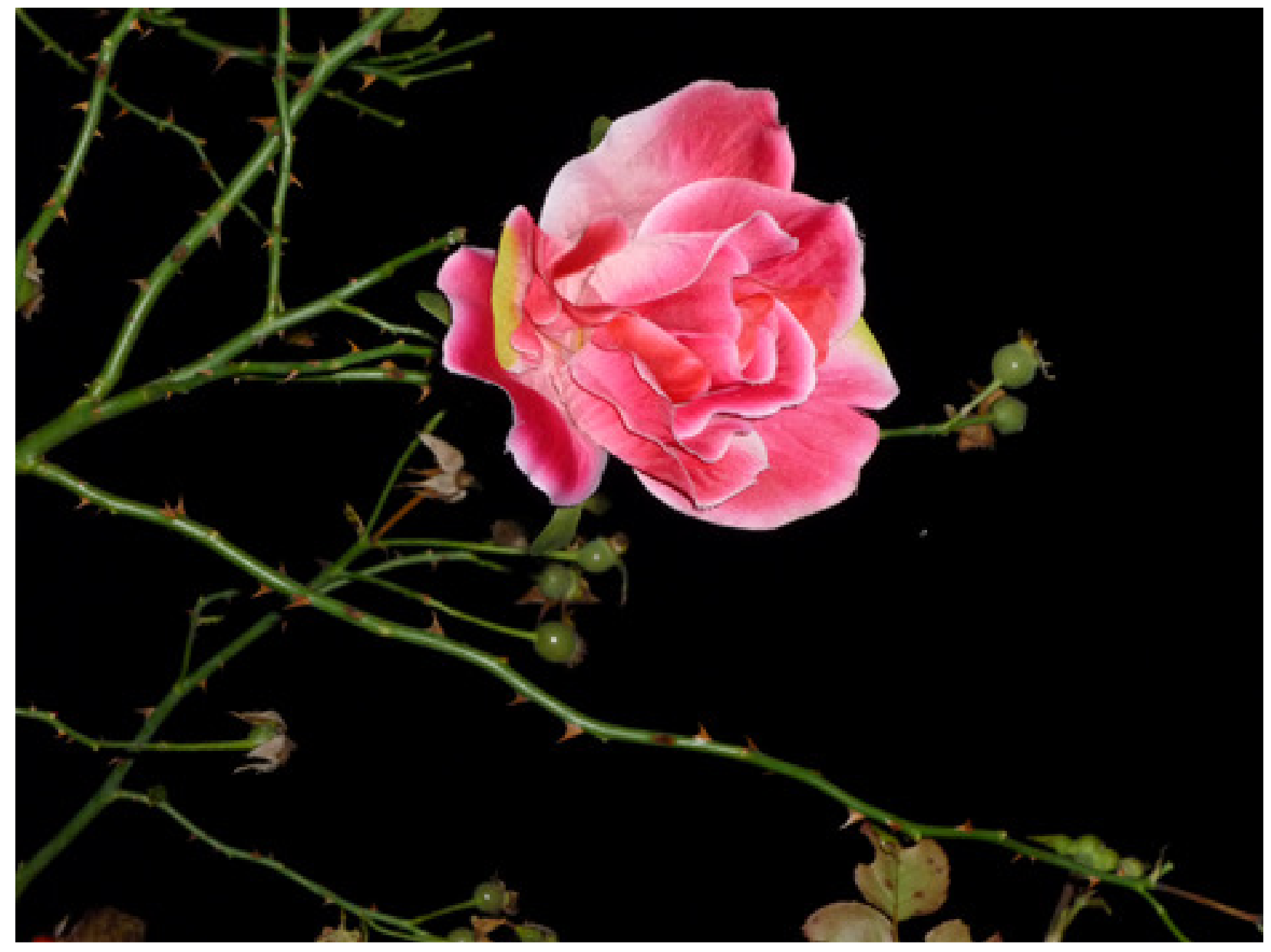

Figure 13: Synthetic Flower (Night), Ink Jet Print, 18x 24 inches, 2009. 


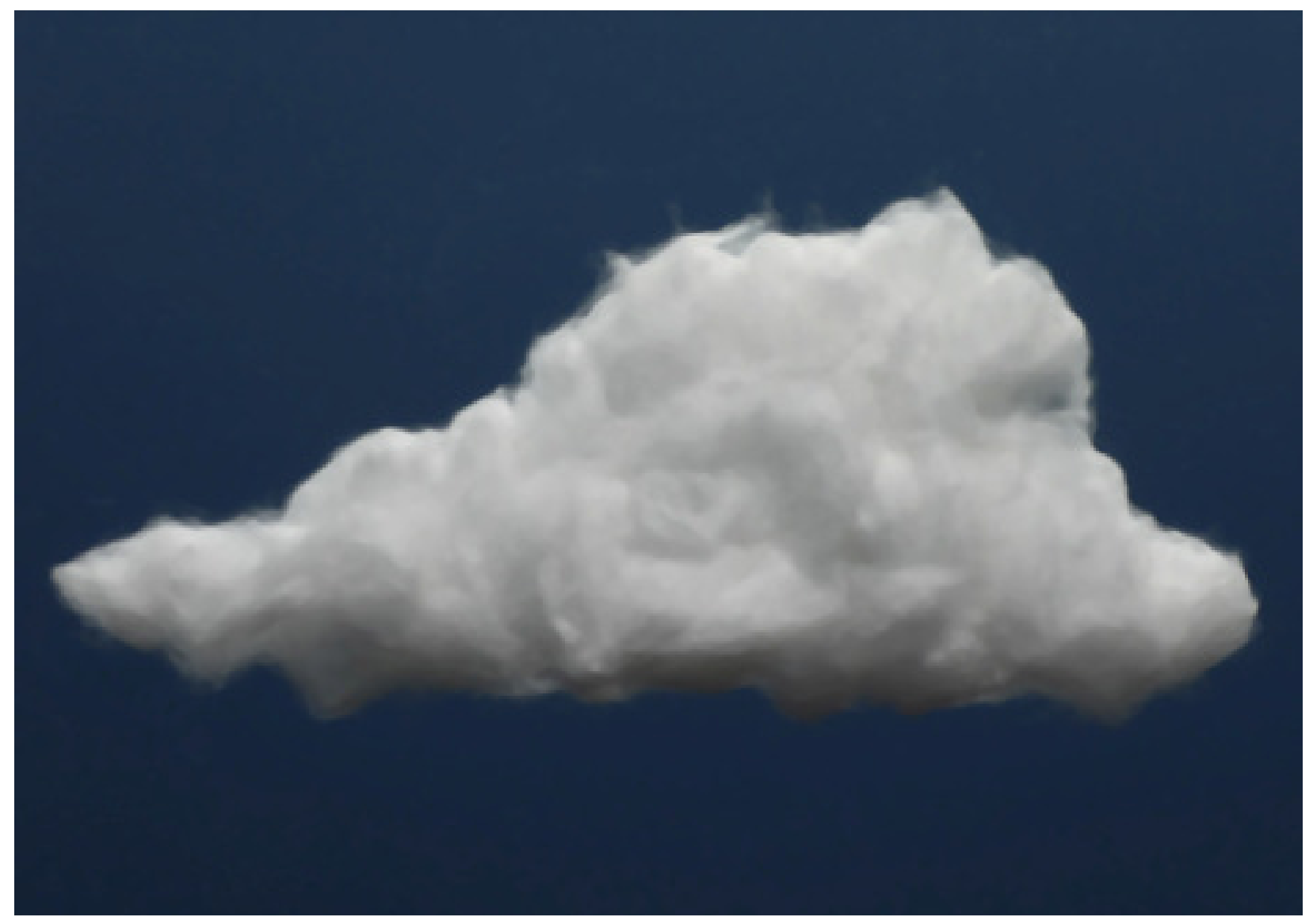

Figure 14: Cotton Cloud 1, Ink Jet Print, 18 x 24 inches, 2009. 


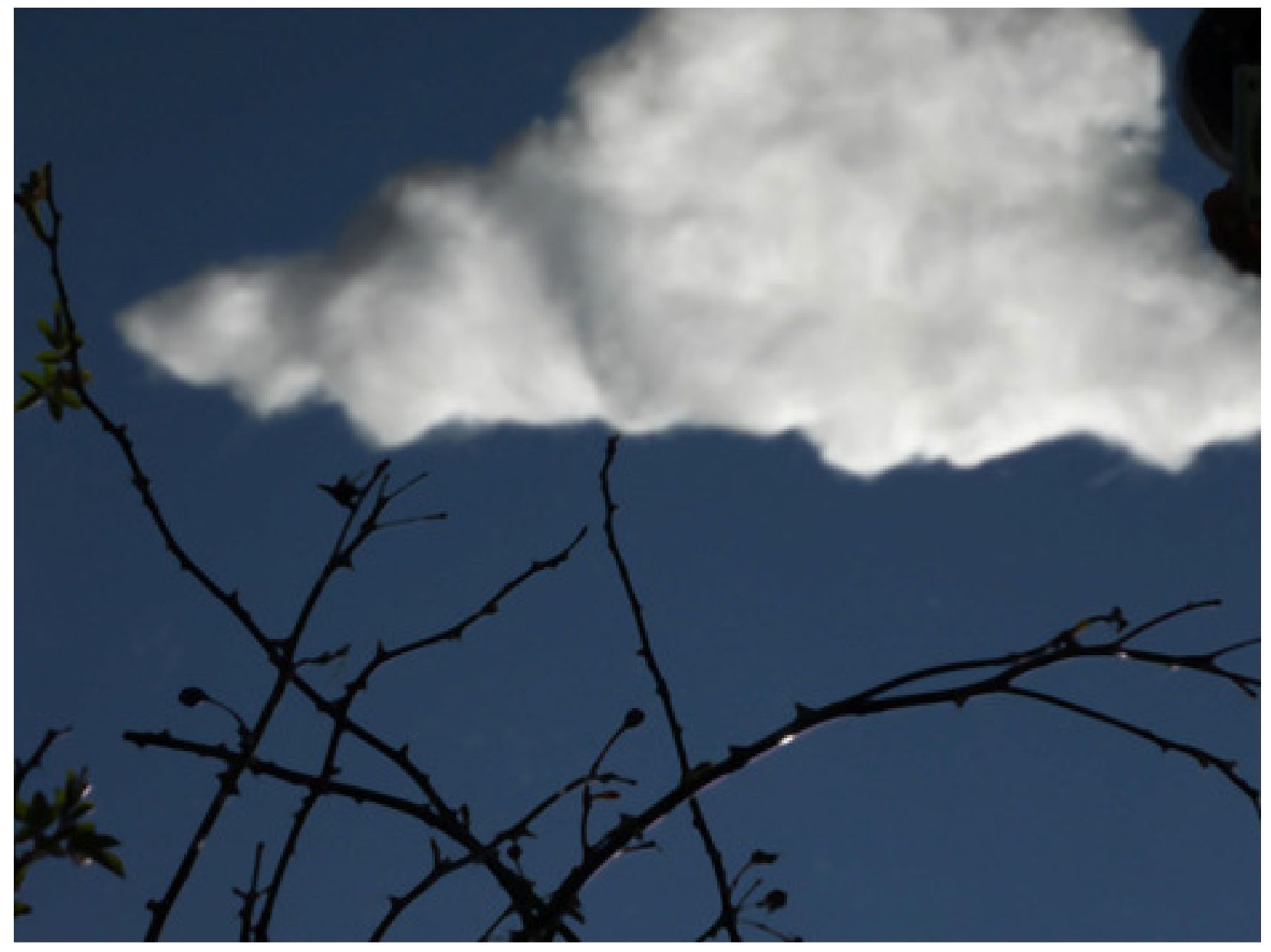

Figure 15: Cotton Cloud 2, Ink Jet Print, 18x24 inches, 2009. 


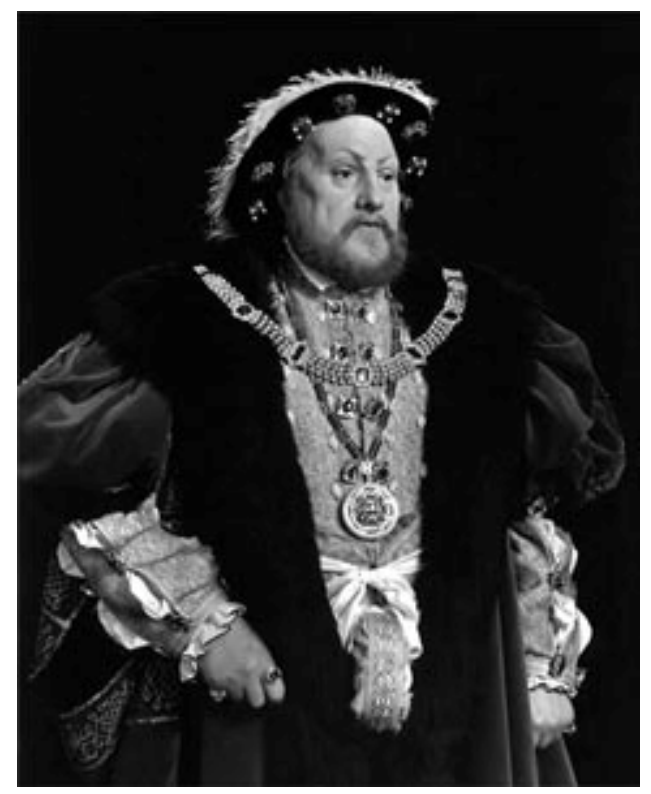

Figure 16: Hiroshi Sugimoto, Henry XIII, 1999. 


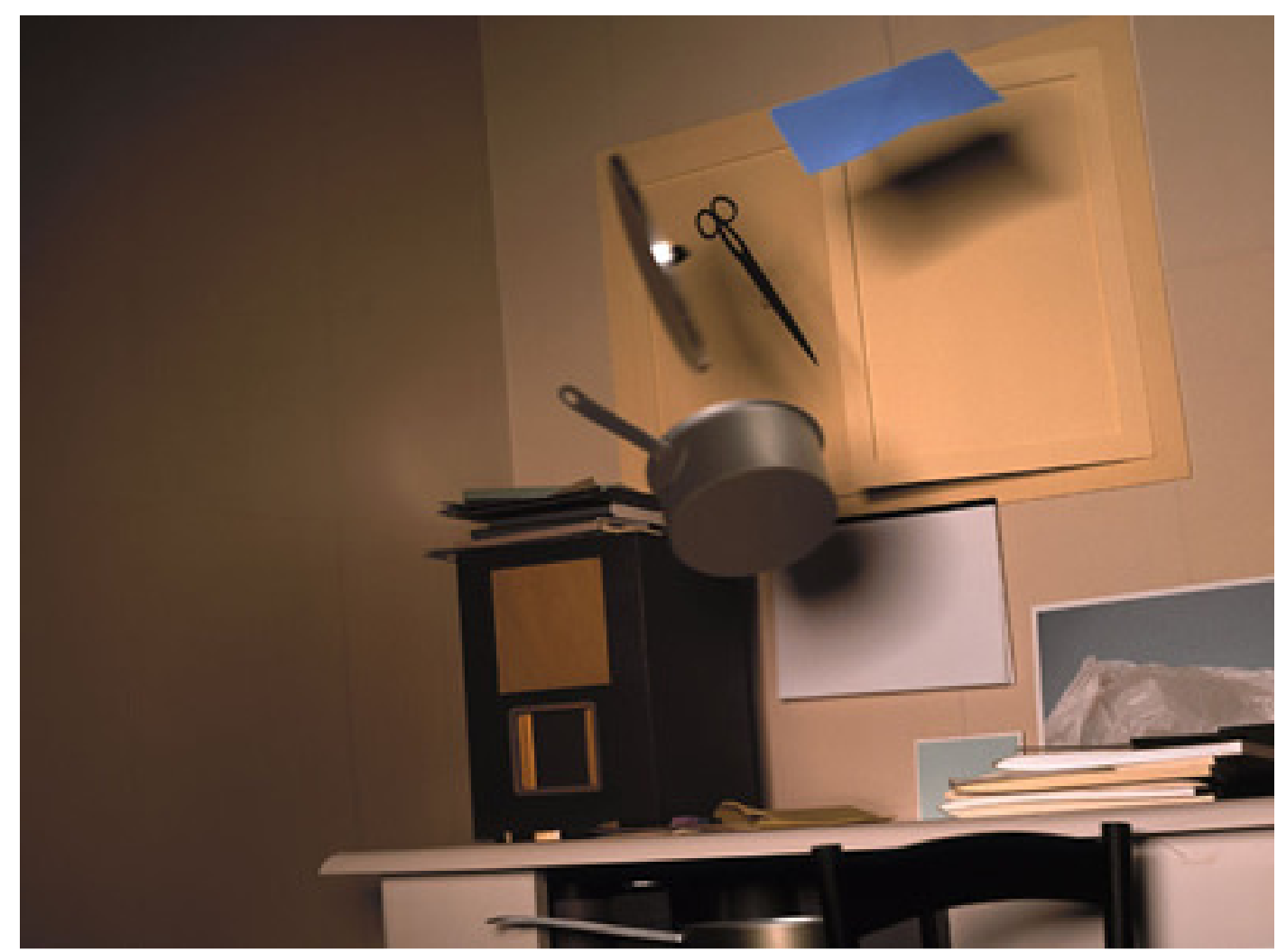

Figure 17: Thomas Demand, Ghost, 2003. 


\section{Bibliography}

Jean Baudrillard. "The Hyper-realism of Simulation." Art in Theory 1900-2000:

An Anthology of Changing Ideas, Edited by Charles Harrison and Paul Wood. Malden, MA:

Blackwell Publishing, 2003.

Baudrillard, Jean. Translated by Ames Hodges. The Conspiracy of Art: Manifestos,Interviews, Essays.

Edited by Sylvere Lotringer. New York, NY, 2005.

Baudrillard, Jean. Symbolic Exchange and Death. Fom Modernism to Postmodernism:An Anthology.

Edited by Lawrence E. Cahoone. Cambridge, MA: Blackwell Publishers Inc., 1996.

Cooper, Diana. www.dianacooper.net. Accessed on April 25, 2009.

Derrida, Jacques, 'The Exorbitant Question of Method' and 'The Engraving and Ambiguities of

Formalism', from Of Grammatology. Art in Theory 1900-2000: An Anthology of Changing Ideas. Edited by Charles Harrison and Paul Wood. Malden, MA: Blackwell Publishing, 2003.

Iversen, Margaret. Beyond Pleasure: Freud, Lacan Barthes. University Park, PA:

The Pennsylvania State University Press, 2007.

Koplos, Janet. "Portraits of Light.” Art in America 2 (February:2006): 82-89.

Lotringer, Sylvere and Paul Virilio. Translated by Michael Taormina.

The Accident of Art. New, NY: Semiotext(e), 2005.

Yablonsky, Linda. "What Makes A Painting A Painting.” ARTnews 104 (April: 2005): 96-101. 


\section{Works from the Exhibition}

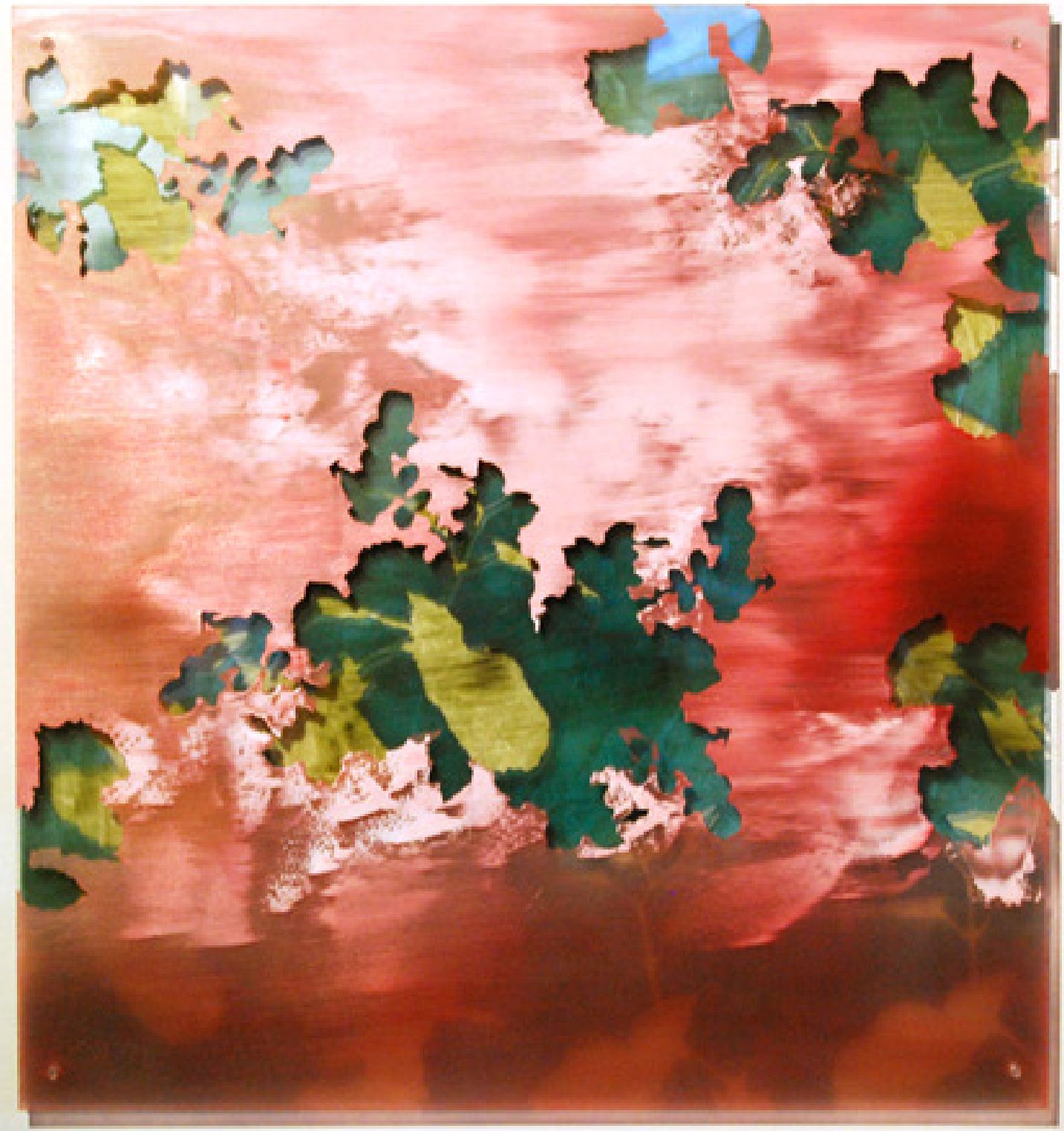

$R B G$ (small), oil on three clear acrylic sheets with clear polycarbonate nuts and bolts, $28 \times 30$ inches, 2009. 


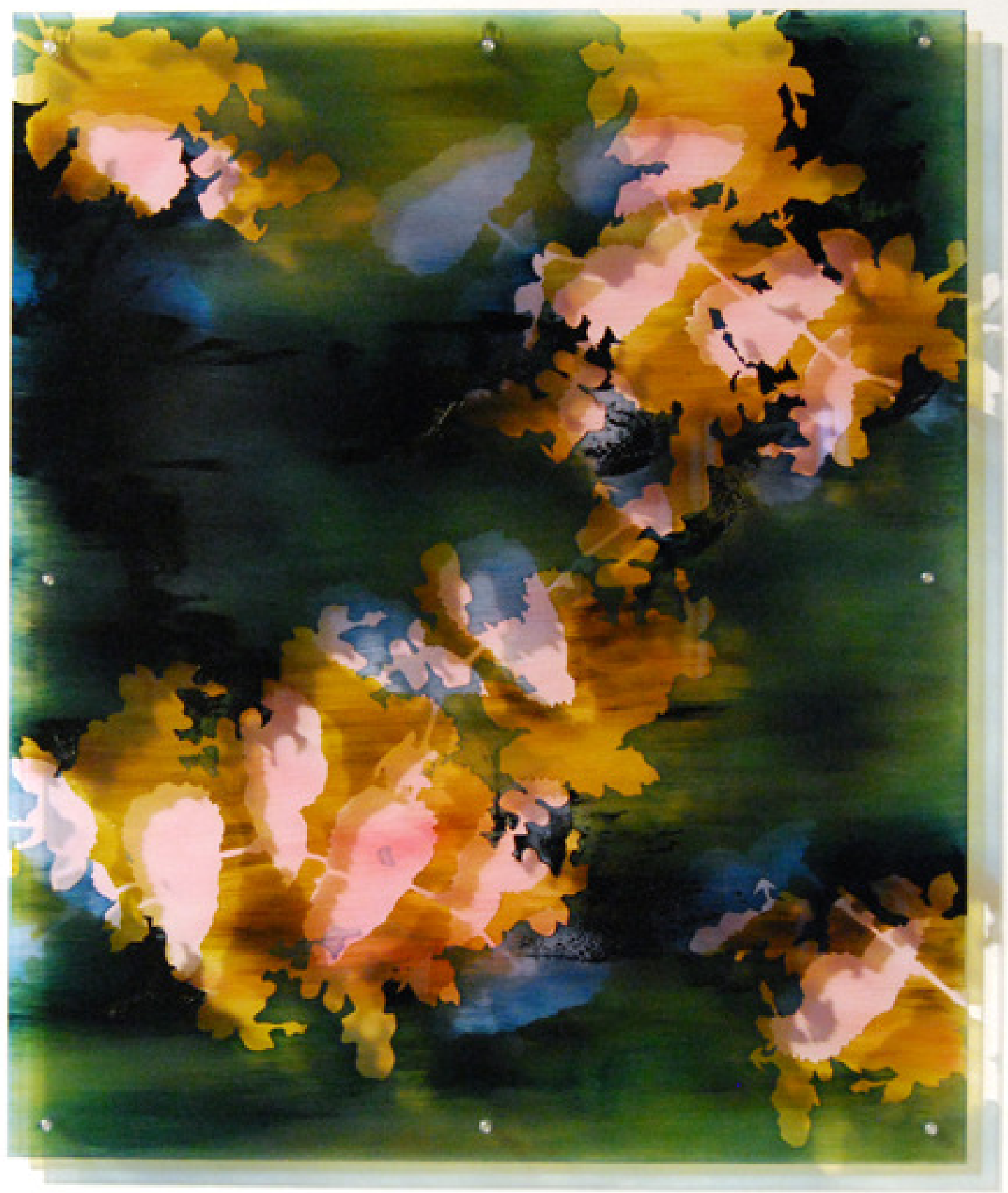

$B G R$, oil on three clear acrylic sheets with clear polycarbonate nuts and bolts, $30 \times 36$ inches, 2009. 


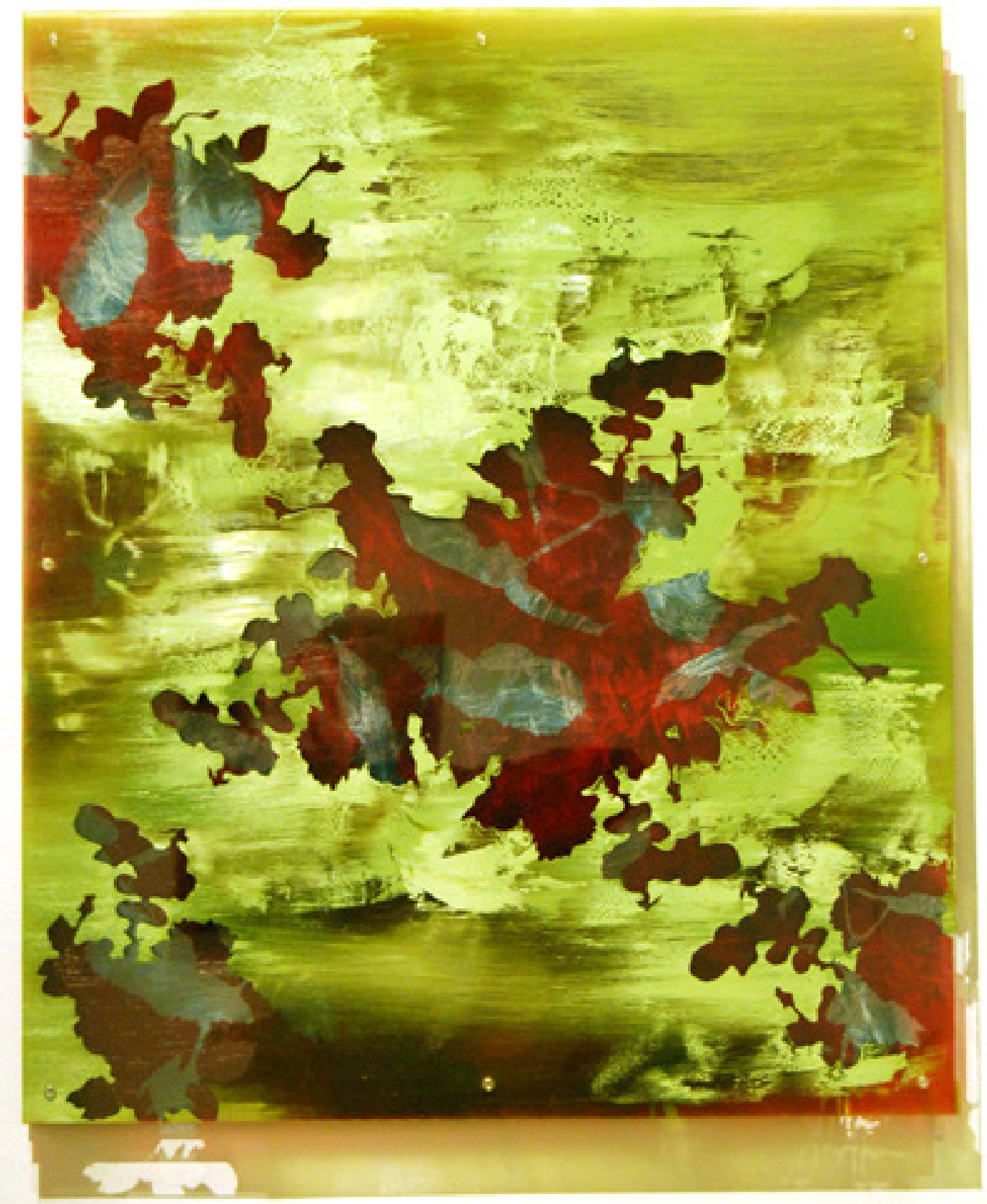

$G R B$, oil on three clear acrylic sheets with clear polycarbonate nuts and bolts, 30 x 36 inches, 2009. 

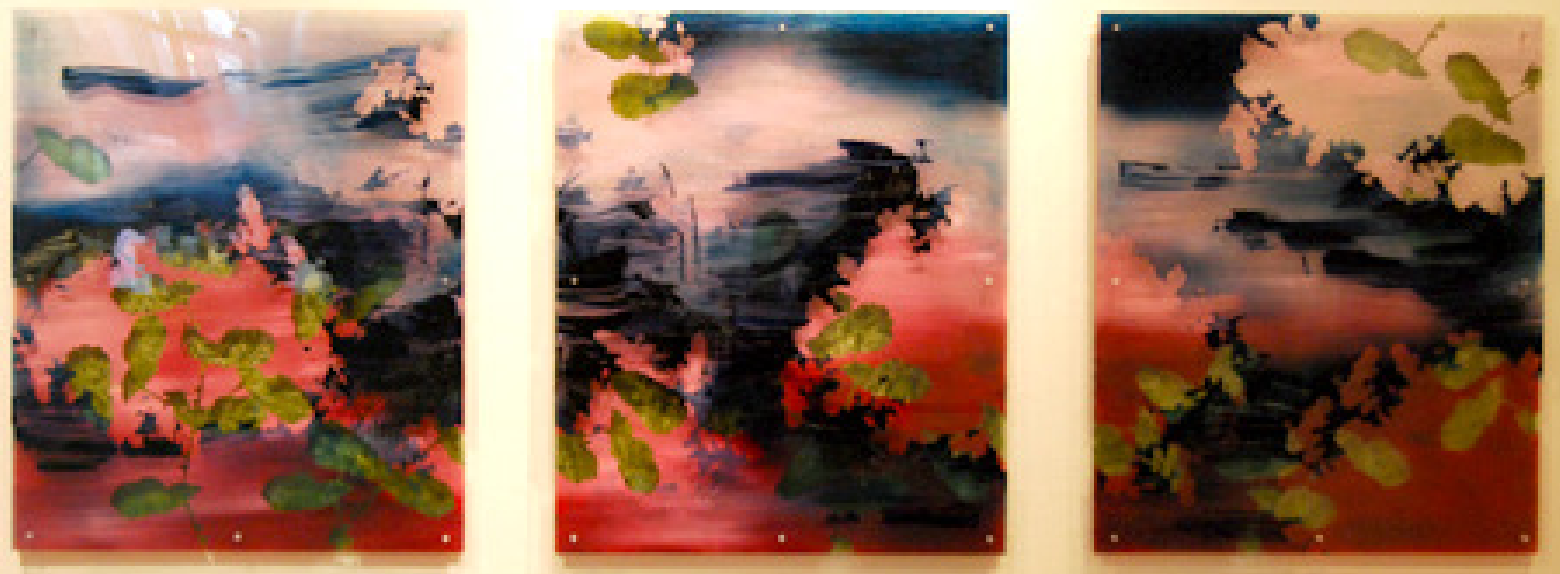

$B R G$ (triptych), oil on three clear acrylic sheets with clear polycarbonate nuts and bolts, 28 x 30 inches each panel, 2009. 


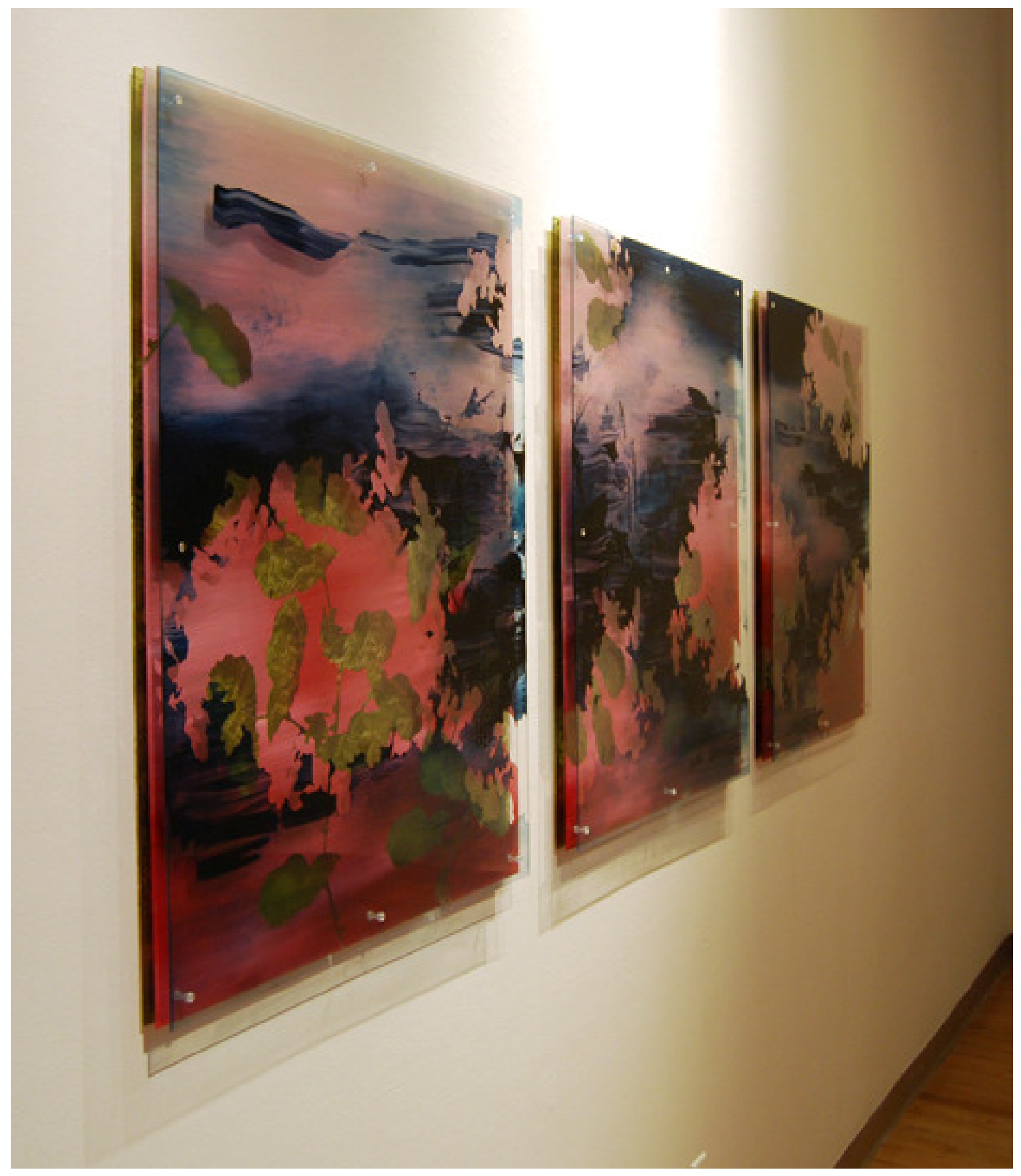

$B R G$ (triptych), installation view, oil on three clear acrylic sheets with clear polycarbonate nuts and bolts, 30 x 36 inches each panel, 2009. 


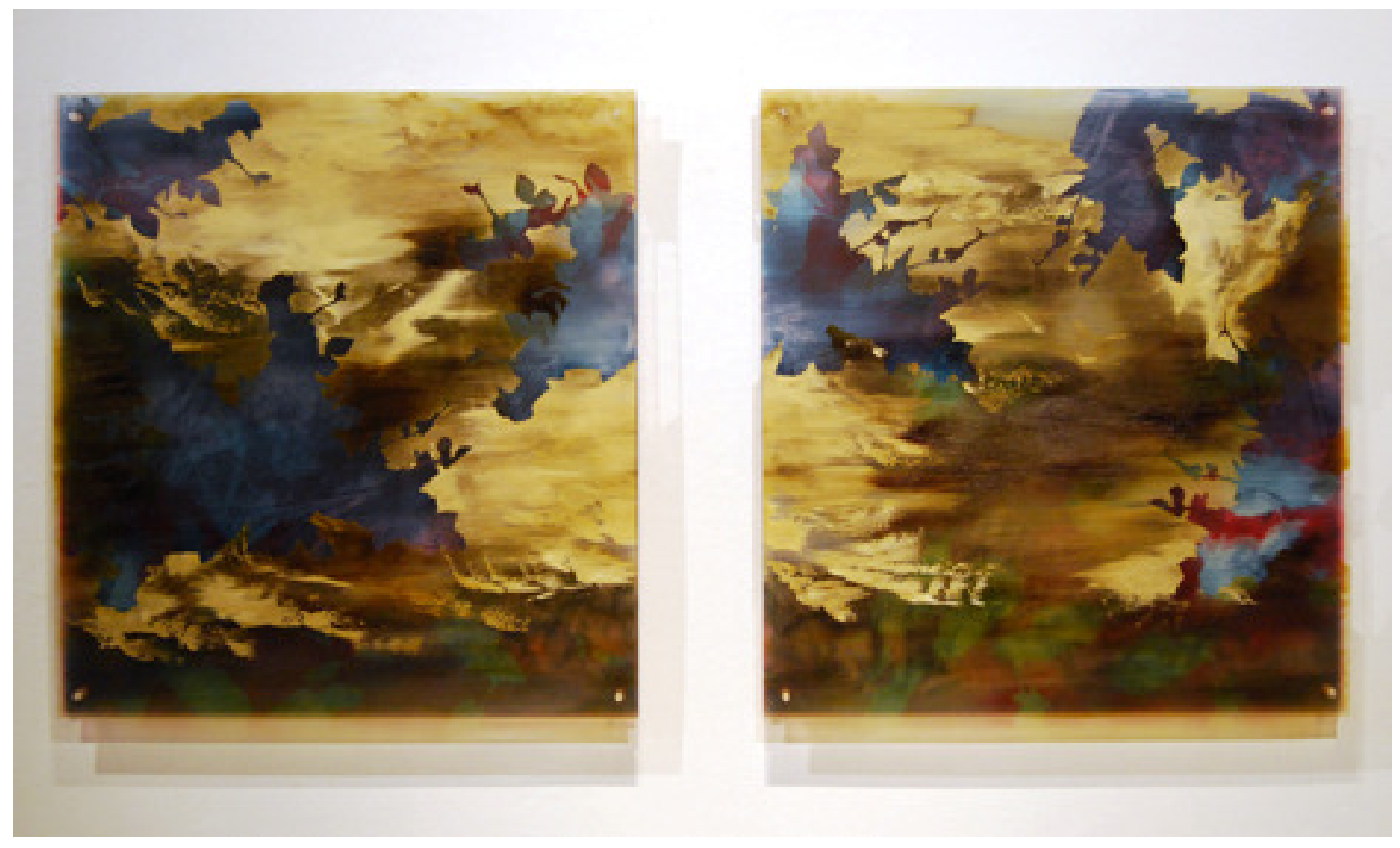

$G R B$ (diptych), oil on three clear acrylic sheets with clear polycarbonate nuts and bolts, $28 \times 30$ inches each panel, 2009. 


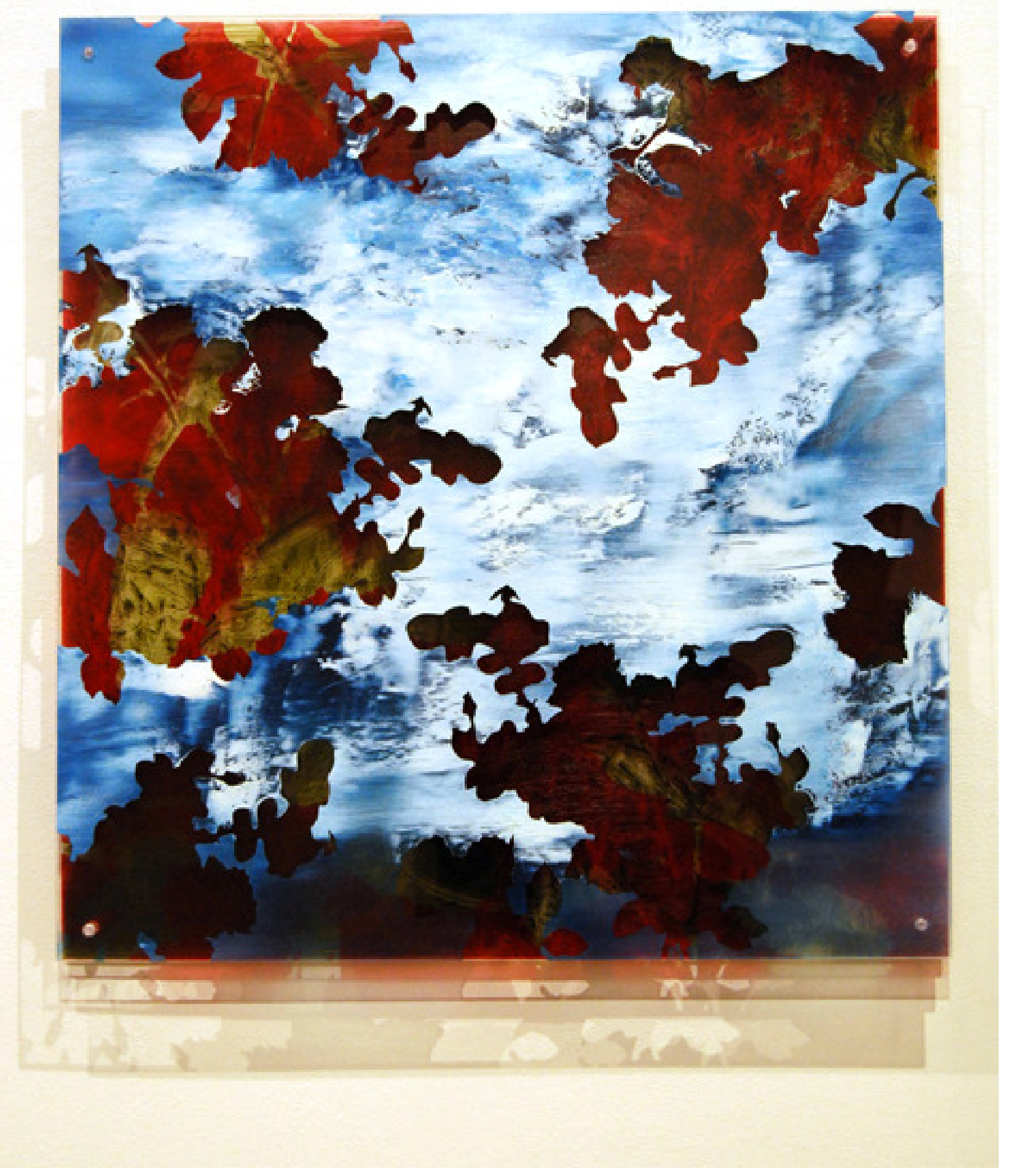

$B R G$ (small), oil on three clear acrylic sheets with clear polycarbonate nuts and bolts, $28 \times 30$ inches, 2009. 


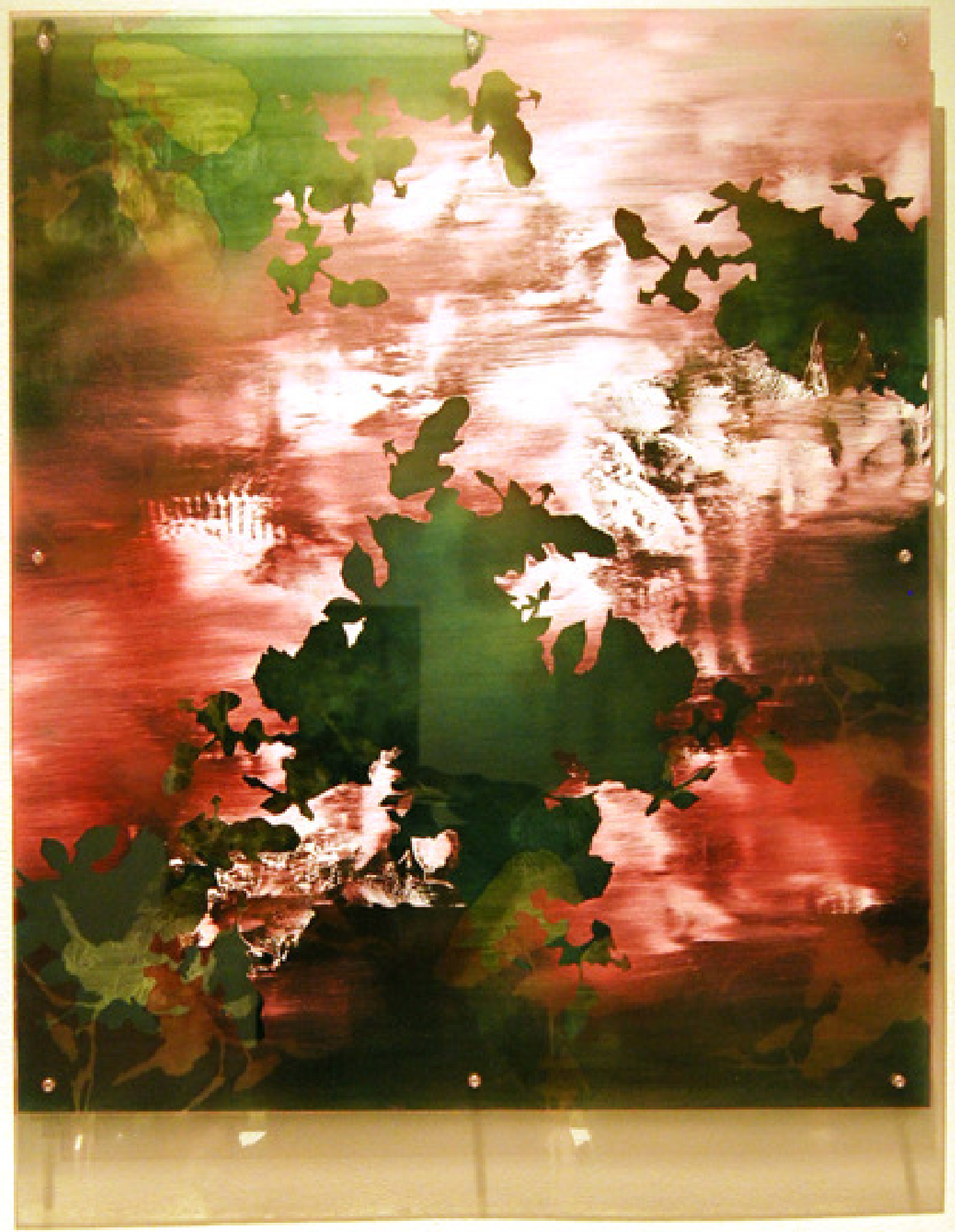

$R B G$ (large), oil on three clear acrylic sheets with clear polycarbonate nuts and bolts, $30 \times 36$ inches, 2009. 


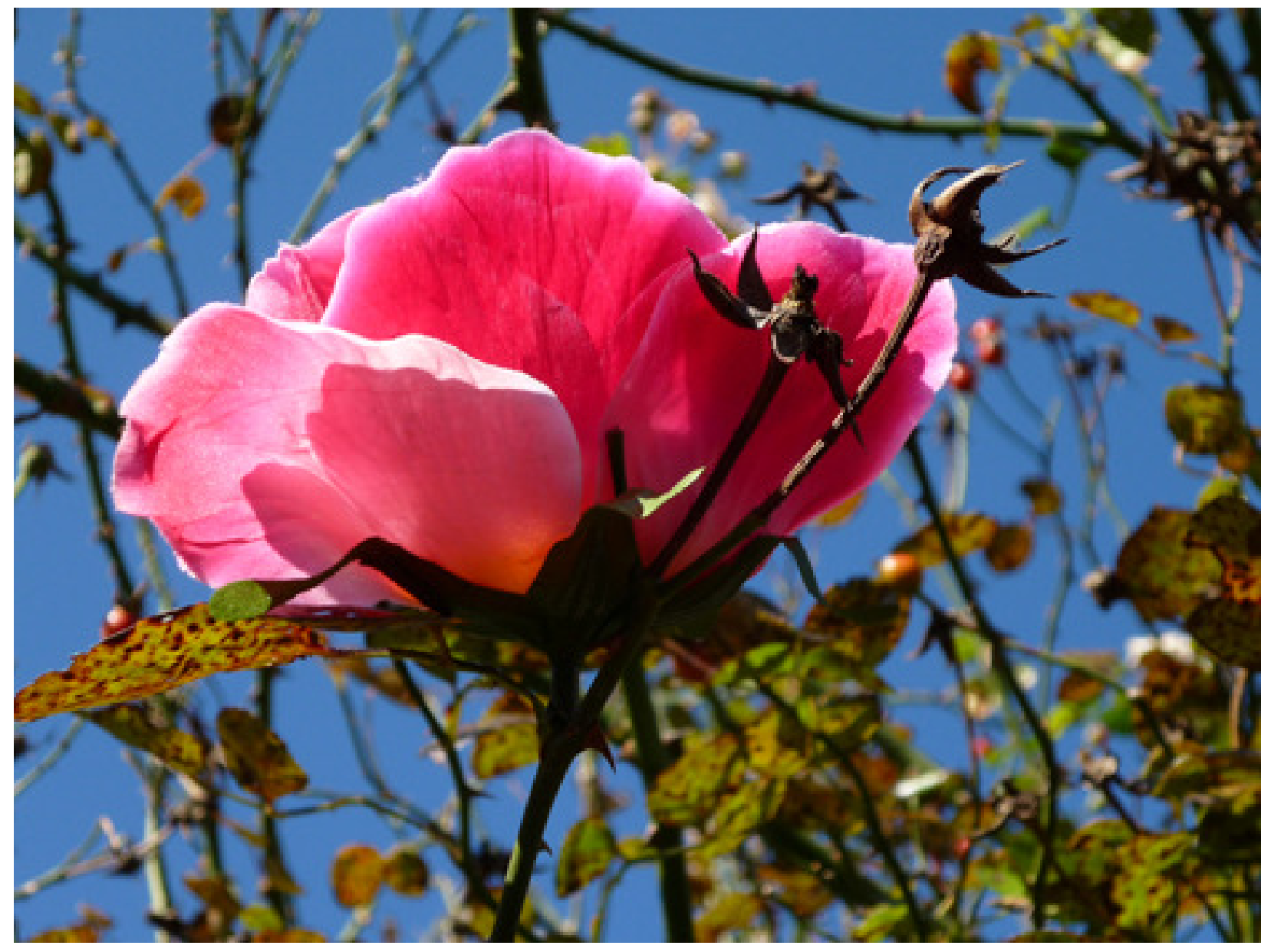

Synthetic Flower (Day), Ink Jet Print, 18 x 24 inches, 2009. 


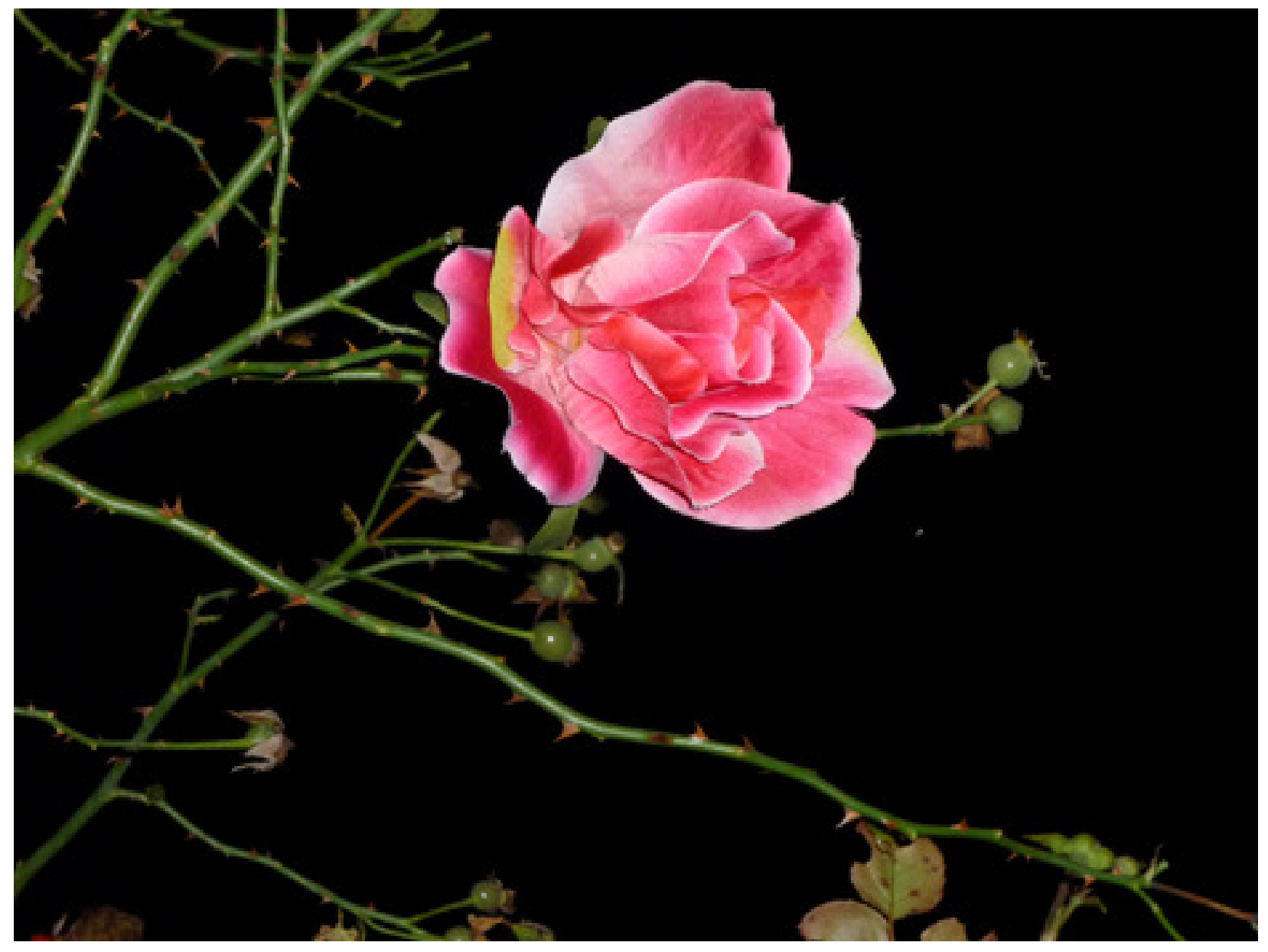

Synthetic Flower 2 (Night), Ink Jet Print, 18x 24 inches, 2009. 


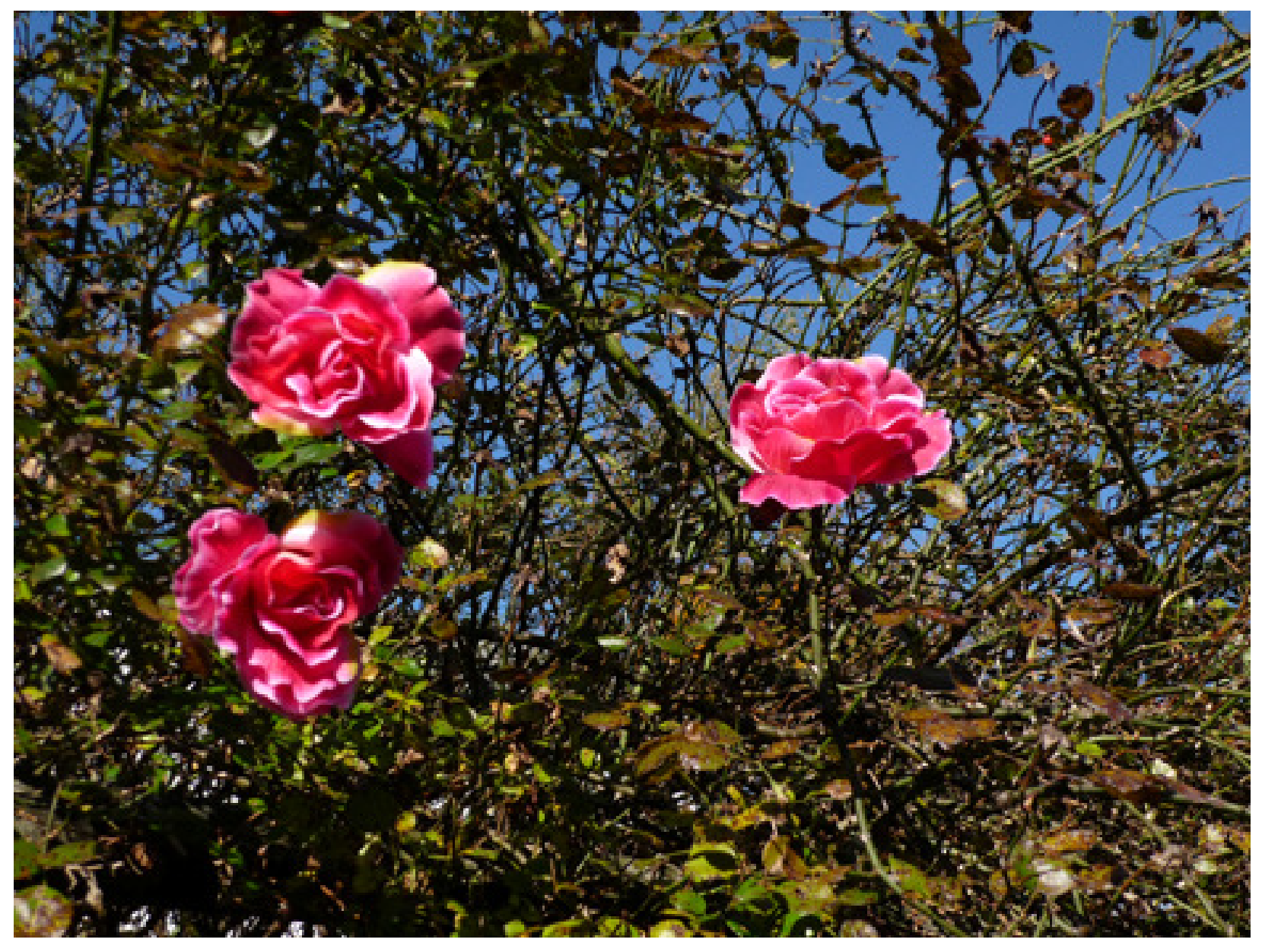

Synthetic Flowers 1, Ink Jet Print, 18x 24 inches, 2009. 


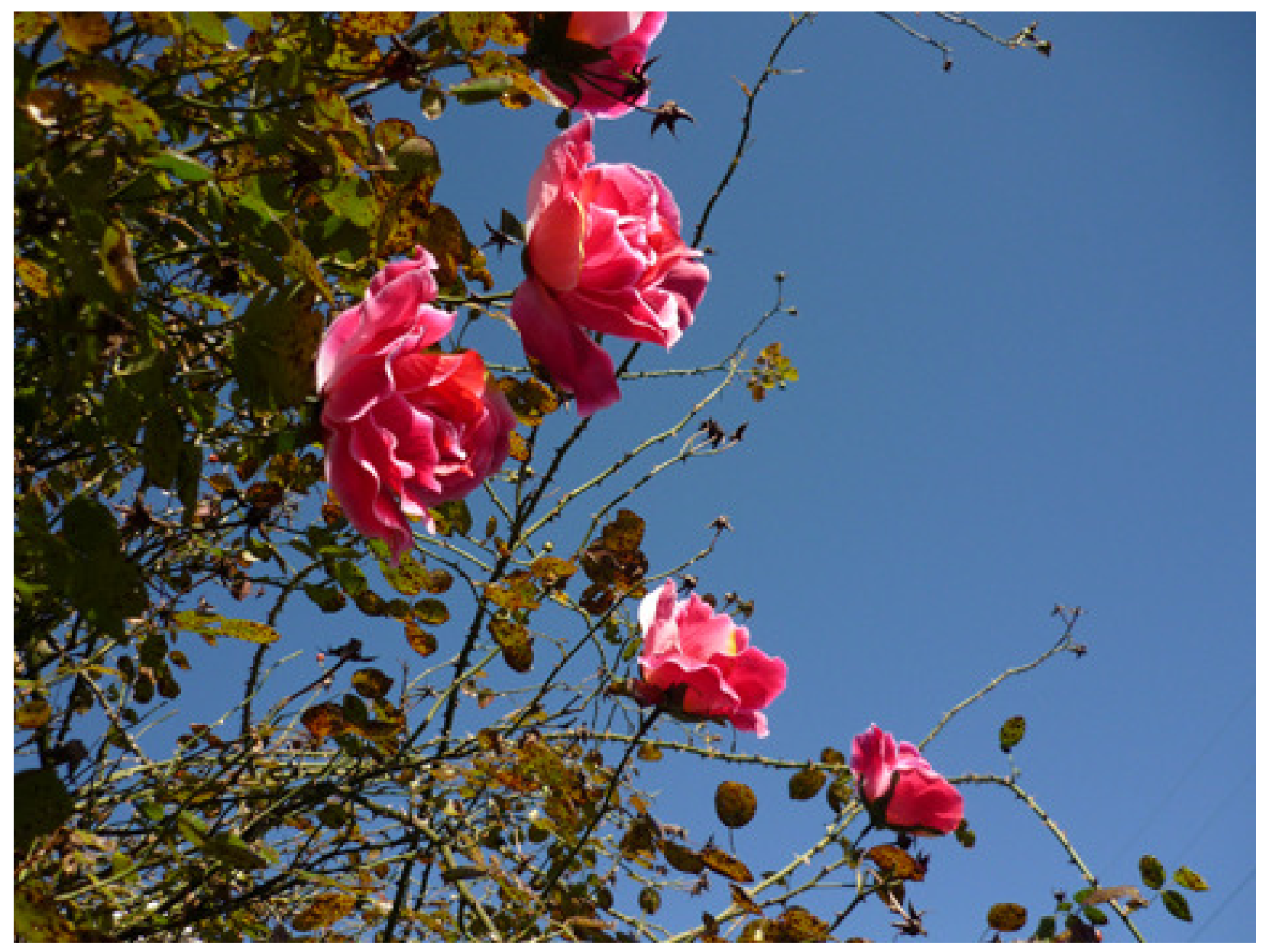

Synthetic Flowers 2, Ink Jet Print, 18x 24 inches, 2009. 


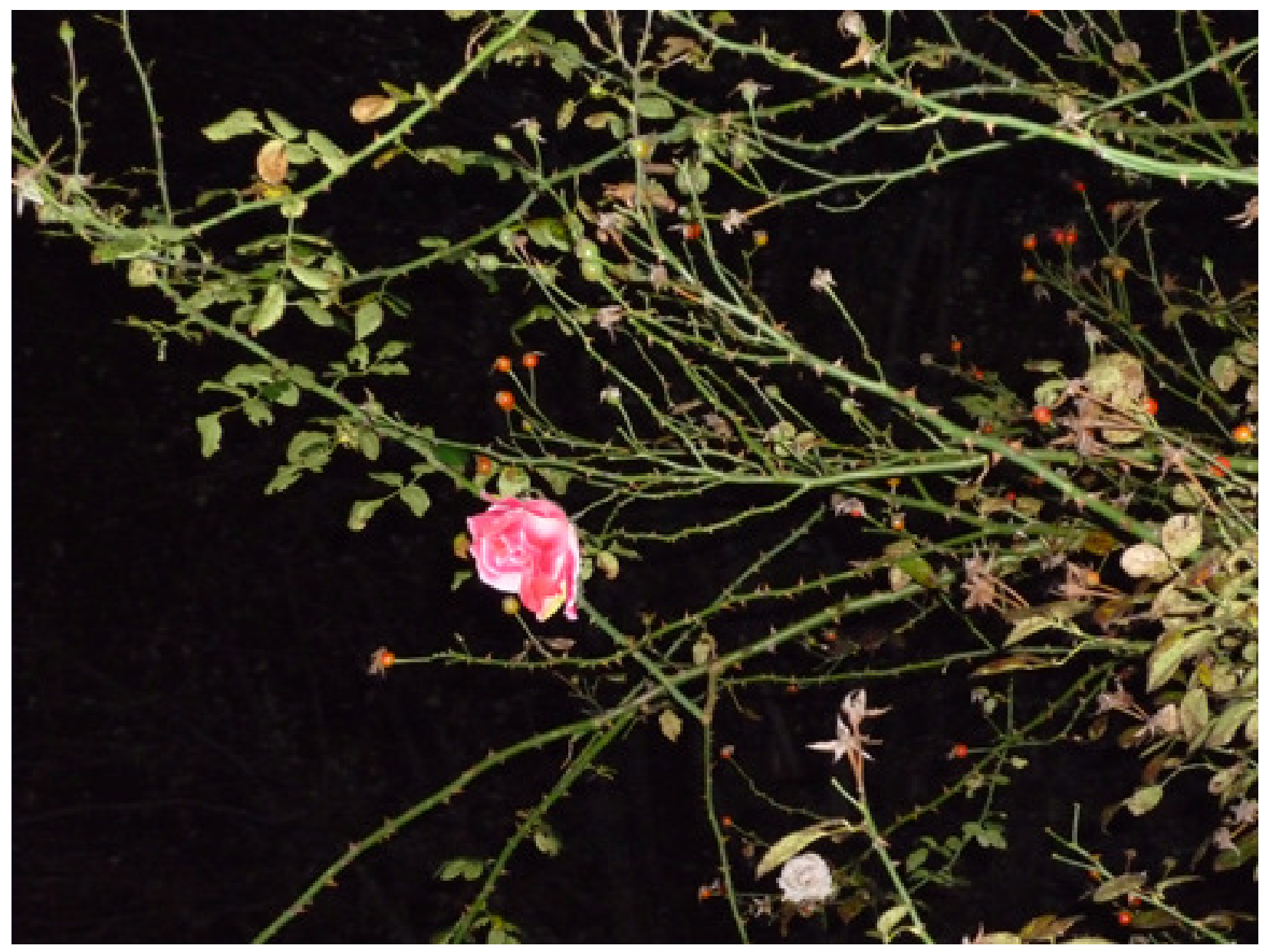

Synthetic Flower 1 (Night), Ink Jet Print, 18x 24 inches, 2009. 


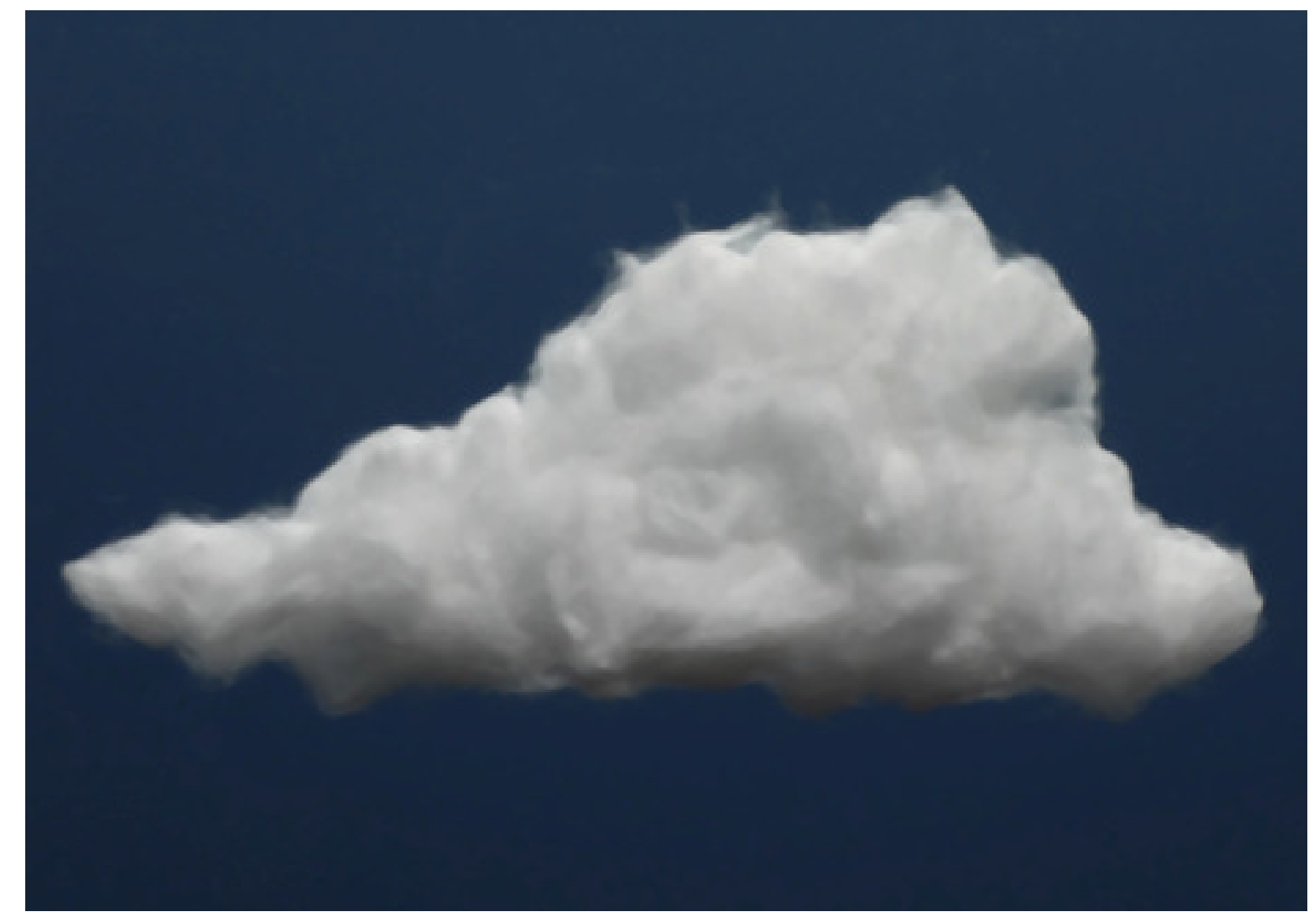

Cotton Cloud 1, Ink Jet Print, 18 x 24 inches, 2009. 


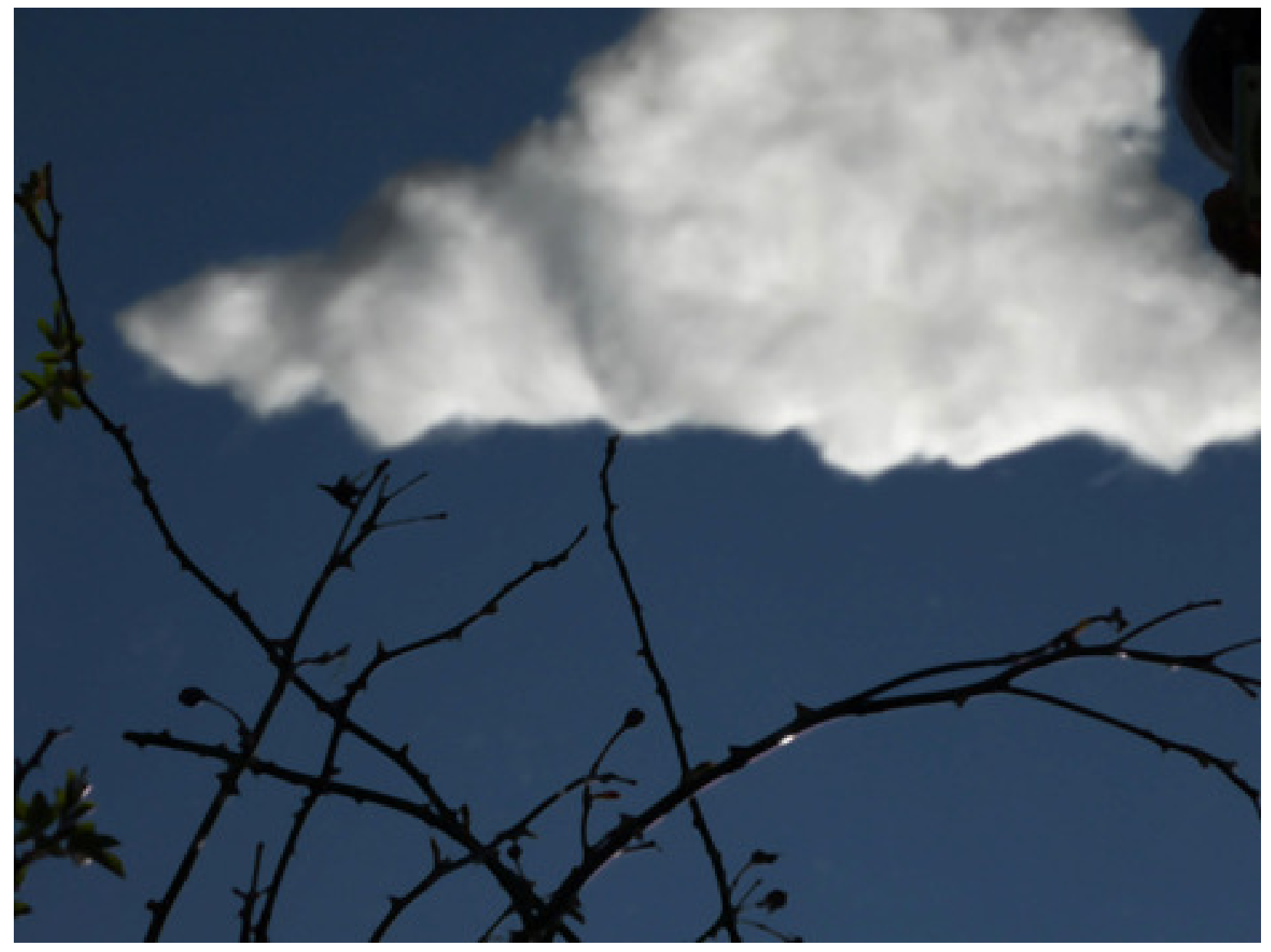

Cotton Cloud 2, Ink Jet Print, 18x24 inches, 2009. 


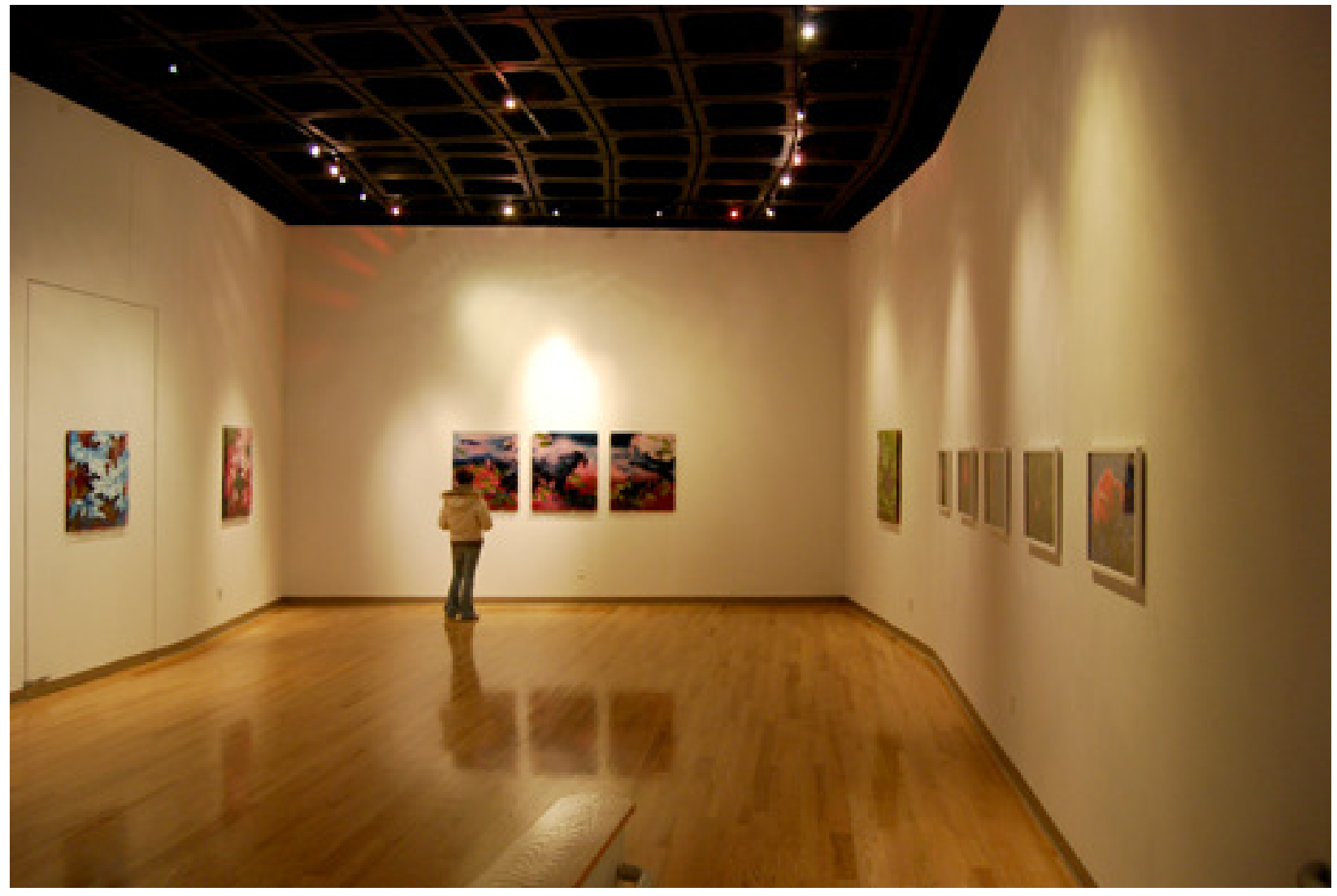

Installation view 1 of the exhibition, (re)construct: exploring objecthood in a digital age. 


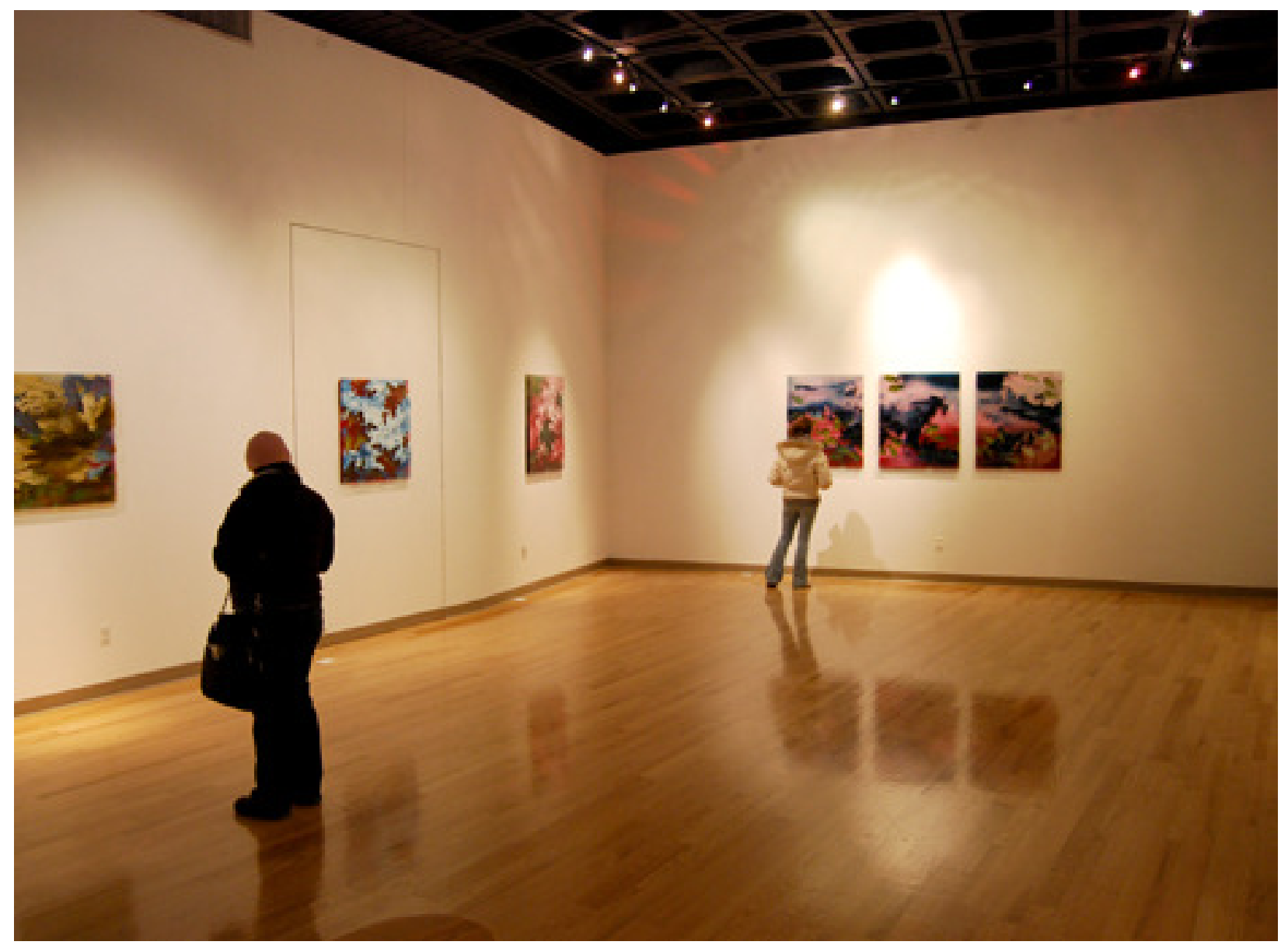

Installation view 2 of the exhibition, (re)construct: exploring objecthood in a digital age. 


\section{C.V.}

Patrick Lee Jones

Born:

1974

Largo, Florida

Education:

2006 Present MFA Candidate, Painting Concentration, West Virginia University, College of Creative Arts, Morgantown, WV

2006 MA in Art with a concentration in the History of Art, West Virginia University, College of Creative Arts, Morgantown, WV

2002 BA Interdisciplinary Studies: Art and History, cum laude, Fairmont State University, Fairmont WV

Solo Exhibitions:

2009 "reconstruct: questioning objecthood in a digital age," MFA Thesis Exhibition, Laura Mesaros Gallery, West Virginia University,

College of Creative Arts, Morgantown, WV

2003 Blue Moose Café, Alternative Art Space, Morgantown, WV

2001 Book-N-Bean Café, Alternative Art Space, Fairmont, WV

$2001 \quad$ Featured Artist, Whetstone,

The Art and Literary Journal of Fairmont State University, Issue 20

Group Exhibitions:

2008 "Mediated," Curated by Amy Bowman, Sweetwater Center for the Arts, Sewickly, PA

2007 "In Medias Res,” Paul Mesaros Gallery, West Virginia University, College of Creative Arts, Morgantown, WV

2006 “N'est Pas Des Tous,” Laura Mesaros Gallery, West Virginia University, College of Creative Arts, Morgantown, WV

2005 "What You Will,” Laura Mesaros Gallery, West Virginia University, College of Creative Arts, Morgantown, WV

2004 “Untitled Exhibition” Laura Mesaros Gallery, West Virginia University, College of Creative Arts, Morgantown, WV 
Publication:

2008

"Mediated," Exhibition Catalog with Essay by Amy Bowman, Curator

Awards and Honors:

2009-2008 Teaching Assistantship Award, Division of Art and Design,

College of Creative Arts, West Virginia University

2006-2004 Teaching Assistantship Award, Division of Art and Design,

College of Creative Arts, West Virginia University

2002

Presidential Award for Excellence in Scholarship, Fairmont State University

Professional Experience:

Lecturer

2008-2007 Art History 101: Appreciation of the Visual Arts, College of Creative Arts, West Virginia University, taught 8 sections

Adjunct Professor

2007 Art 1140: Art Appreciation,

Pierpont Technical and Community College of Fairmont State University, taught 1 section

Instructor of Record

2009 Art 109: Drawing 1 for Non-Majors, Division of Art and Design, College of Creative Arts, West Virginia University, taught 1 section

Art 105: Survey of Western Art 1 for Non-Majors, Division of Art and Design, College of Creative Arts, West Virginia University, taught 1 section

Art 112: Drawing 2 for Majors, Division of Art and Design, College of Creative Arts, West Virginia University, taught 1 section

2008 Art 109: Drawing 1 for Non-Majors, Division of Art and Design, College of Creative Arts, West Virginia University, taught 1 section

2008-2005 Art History 101: Appreciation of the Visual Arts, Division of Art and Design, College of Creative Arts, West Virginia University, taught 10 sections

Art 110: Drawing 2 for Non-Majors, Division of Art and Design, College of Creative Arts, West Virginia University, taught 1 section

2006 Art 106: Survey of Western Art 2 for Non-Majors, Division of Art and Design, College of Creative Arts, West Virginia University, taught 1 section 
Guest Lectures

2007 "Minimalism," Art History 553: Contemporary Art History,

Division of Art and Design, College of Creative Arts, West Virginia University

2007 "Minimalism,” Art History 353: Contemporary Art History,

Division of Art and Design, College of Creative Arts, West Virginia University

2006 “German Neo-Expressionism,” Art History 553: Contemporary Art History, Division of Art and Design, College of Creative Arts, West Virginia University

2006 “German Neo-Expressionism,” Art History 353: Contemporary Art History, Division of Art and Design, College of Creative Arts, West Virginia University 